\title{
Immunomodulatory Effects of Hemagglutinin- (HA-) Modified A20 B-Cell Lymphoma Expanded as a Brain Tumor on Adoptively Transferred HA-Specific $\mathrm{CD4}^{+} \mathrm{T}$ Cells
}

\author{
Valentin P. Shichkin ${ }^{1,2}$ and Roman M. Moriev ${ }^{1}$ \\ ${ }^{1}$ Department of Immunology, University "Ukraine”, 23 Lvivska Street, Building 2, Room 301, Kyiv 03115, Ukraine \\ ${ }^{2}$ Department of Chemical and Biomolecular Engineering, Whiting School of Engineering, Johns Hopkins University, \\ Baltimore, MD 21218, USA \\ Correspondence should be addressed to Valentin P. Shichkin; shvp@gala.net
}

Received 28 August 2013; Accepted 6 December 2013; Published 16 February 2014

Academic Editors: E. Izbicka and A. A. Manfredi

Copyright (c) 2014 V. P. Shichkin and R. M. Moriev. This is an open access article distributed under the Creative Commons Attribution License, which permits unrestricted use, distribution, and reproduction in any medium, provided the original work is properly cited.

\begin{abstract}
Previously, the mouse A20 B-cell lymphoma engineered to express hemagglutinin (HA) antigen (A20HA) was used as a systemic tumor model. In this work, we used the A20HA cells as a brain tumor. HA-specific CD4 ${ }^{+} \mathrm{T}$ cells were transferred intravenously in a tail vein 5 days after A20HA intracranial inoculation and analyzed on days 2, 9, and 16 after the adoptive transfer by different methods. The transferred cells demonstrated state of activation as early as day 2 after the adoptive transfer and most the of viable HA-specific cells became anergic on day 16. Additionally, symptoms of systemic immunosuppression were observed in mice with massive brain tumors at a late stage of the brain tumor progression (days 20-24 after the A20HA inoculation). Despite that, a deal of HA-specific $\mathrm{CD}^{+}{ }^{+} \mathrm{T}$ cells kept the functional activity even at the late stage of A20HA tumor growth. The activated HA-specific $\mathrm{CD}^{+}{ }^{+} \mathrm{T}$ cells were found also in the brain of brain-tumor-bearing mice. These cells were still responding to reactivation with HApeptide in vitro. Our data support an idea about sufficient role of both the tumor-specific and -nonspecific mechanisms inducing immunosuppression in cancer patients.
\end{abstract}

\section{Introduction}

While gliomas are the most common primary malignant tumors of brain, lymphomas also contribute significantly in frequency of primary central nervous system (CNS) tumors, especially in patients receiving an immunosuppressive therapy.

Induction of immune response to tumors located in brain is limited by blood brain barrier (BBB) that bounds access of $\mathrm{T}$ cells to the CNS as well as failure of brain environment to activate infiltrating $\mathrm{T}$ cells fully $[1,2]$. Although the BBB may pose an obstacle for migration of naive $\mathrm{T}$ cells into brain, there is considerable evidence that activated $\mathrm{T}$ cells are able to pass through the $\mathrm{BBB}$ and enter brain for antigen surveillance [3-5]. Particularly, circulating $\mathrm{CD} 8^{+} \mathrm{T}$ lymphocytes activated outside brain with tumor-specific antigens may enter into the brain and develop a local cytotoxic response against tumor
[2, 6-11]. Certain evidences indicate that $\mathrm{CD} 4^{+} \mathrm{T}$-helper (Th) cells can also enter into brain $[11,12]$, and they are an equally critical component of antitumor immune response [11, 1317]. However, tumor-specific $\mathrm{CD} 4^{+} \mathrm{T}$ cells can be rendered tolerant (anergic) when they encounter antigen in absence of a costimulatory signal [18-20]. Anergic $\mathrm{CD} 4^{+} \mathrm{T}$ cells are neither deleted nor altered with regard to levels of $\mathrm{T}$ cell receptor for antigen (TCR) and coreceptor molecules, such as B7, but are refractory to an antigenic stimulus that would activate naive $\mathrm{T}$ cells $[21,22]$. Though tumor-specific $\mathrm{CD} 4^{+}$ Th cells are necessary for generation of potent antitumor immunity, there still are little known about fate of these Th cells during a lymphoma progression in brain.

Mouse A20 B-cell lymphoma modified with influenza hemagglutinin (HA) gene to express HA antigen (A20HA) was developed as an experimental system allowing the quantitative determination of systemic tumor progression 
effects on population of naive TCR clonotypic $\mathrm{CD} 4{ }^{+}$Th cells that is specific for HA antigen in terms of their proliferation versus depletion and state of activation versus anergy [4, 20, 21, 23]. A20 cells express high levels of MHC class I and class II molecules as well as constitutively low levels of $\mathrm{T}$ cell costimulatory molecules CD80 (B7-1) and CD86 (B7-2), and they are able to present both exogenous and endogenous antigens [20]. This tumor behaves in vivo similar to many forms of human B-cell lymphoma. Systemic intravenous (i.v.) injection of A20 cells results in spread to spleen, mesenteric lymph nodes, and liver. At late stages, the cells can also be found in bone marrow and blood [16]. Thus, this approach allows for determining changes in phenotype and function of adoptively transferred HA-specific $\mathrm{CD}^{+}{ }^{+} \mathrm{T}$ cells including their proliferation, depletion, state of activation, and anergy following exposure to $\mathrm{HA}$ antigen in tumor-bearing mice $[16,20,21,24]$.

In this study, we used A20HA cells as a brain tumor experimental model to evaluate immunomodulatory effects of a brain lymphoma on adoptively transferred HA-specific $\mathrm{CD}^{+}{ }^{+} \mathrm{T}$ cells. We have established survival rate of A20HA brain-tumor-bearing mice and demonstrated possibility of adoptively transferred $\mathrm{CD}^{+}{ }^{+} \mathrm{T}$ cells to the tumor-specific activation in vivo as well as development of the tumorspecific anergy in process of the brain tumor progression. We also demonstrated that although the tumor-specific anergy as well as symptoms of systemic immunosuppression is developed in A20HA brain tumor-bearing mice, there still exist $\mathrm{CD} 4^{+}$Th cells responding to HA-specific restimulation even at late stages of the brain tumor progression, and the activated HA-specific T cells could be found in the brain. These results provide important insight into continued efforts to develop combined chemoimmunotherapy modalities for patients with brain lymphomas, which could include systemic adoptive transfer of tumor-specific T cells and DNA vaccination as well as local cytokine and chemotherapy delivery $[11,17,25-27]$.

\section{Materials and Methods}

2.1. Mice. BALB/c female mice, 4- to 6-week old, were obtained from the National Institutes of Health (Frederick, MD). TCR transgenic mice expressing $\alpha \beta$ TCR specific for influenza HA peptide (amino acids 110-120) were kindly provided by Prof. H. Levitsky. These mice were crossed to a BALB/c background for more than ten generations before using and were heterozygous for the transgene (HA MHC $\mathrm{II}^{+/-}$Thyl. $\left.1^{+/-} 6.5^{+/-}\right)$. All experiments involving the use of mice were performed in accordance with protocols approved by the Animal Care and Use Committee of the Johns Hopkins University School of Medicine.

2.2. Antibodies. Biotin-labeled rat anti-TCR antibodies 6.5, FITC-conjugated goat anti-mouse CD4, and FITCconjugated anti-CD44 antibodies were purchased from Caltag (South San Francisco, CA). Cy-Chrome-conjugated rat anti-mouse CD4 (RM4-5), FITC-conjugated rat antimouse CD44 (IM7), and PE- or perCp-conjugated mouse anti-rat/mouse Thy1.1 (OX-7) antibodies were purchased from PharMingen (San Diego, CA).

2.3. A20HA Cell Line. A20HA cell line (BALB/c background) was created by electroporation and plasmid transfection of A20 cells with HA gene [16] and was kindly provided by Prof. $\mathrm{H}$. Levitsky. The cells were cultured at $37^{\circ} \mathrm{C}$ in $5 \% \mathrm{CO}_{2}$ atmosphere with neomycin analogue G418 $(400 \mu \mathrm{g} / \mathrm{mL})$ in RPMI 1640 media supplemented with fetal calf serum (10\%), penicillin/streptomycin $(50 \mathrm{U} / \mathrm{mL})$, L-glutamine $(2 \mathrm{mM})$, and 2mercaptoethanol $(50 \mu \mathrm{M})$ as described [20]. A stereotactic technique was used for intracranial (i.c.) injection of A20HA cells in the left parietal lobe of brain of BALB/c mice $\left(1 \times 10^{4}\right.$ or $5 \times 10^{4}$ cells) in a volume of $2 \mu \mathrm{L}$ Hanks Buffered Salt Solution (HBSS) as described [6]. For systemic i.v. inoculation, A20HA cells $\left(1 \times 10^{6}\right.$ in $200 \mu \mathrm{L}$ HBSS $)$ were injected into a tail vein as described [20].

2.4. Adoptive Transfer. Lymph nodes and spleens were collected from TCR transgenic BALB/c mice from estimate one donor to four recipients [21], homogenized in RPMI-1640 media, and passed over nylon mesh. After lysis of red cells, lymphocytes were washed in HBSS and percentage of HAspecific T cells positive for CD4 and clonotypic TCR (Thyl.1 $1^{+}$ and/or $6.5^{+}$) was determined by FACS. The cells were injected i.v. into a tail vein of recipient $\mathrm{BALB} / \mathrm{c}$ mice (three mice per group) such that a total of $2.5 \times 10^{6} \mathrm{CD} 4^{+}$TCR clonotypic $\mathrm{T}$ cells [20] were transferred to each recipient 5 days after the tumor challenge.

2.5. Mouse Survival Experiments and Histopathology. All mouse survival experiments following A20HA i.c. challenge included five mice per group. Each experiment was repeated at least twice. Animals were monitored for any signs of neurotoxicity and autopsied to confirm that death was due to a brain tumor. Brains, spleens, livers, thymuses, and lymph nodes were collected on days 7, 14, and 21 after the tumor inoculation, fixed in $10 \%$ formalin, blocked in paraffin, and sectioned in $10 \mu \mathrm{m}$ sections. Each section was then stained with eosin and hematoxylin and analyzed under a light microscope. Photomicrographs were taken with 10-, 20-, and 40-fold magnifications or direct scanning.

2.6. RT-PCR and In Vitro Cell Cultures for Metastases. Spleens, lymph nodes, and livers were collected from three mice per group on days 14 and 21 after i.c. $\left(5 \times 10^{4}\right.$ cells $)$ and i.v. $\left(1 \times 10^{6}\right.$ cells $)$ A20HA inoculation. After red cell lysis, cells were washed in HBSS and RNA was extracted from $2 \times$ $10^{6}$ cells using a QIAGEN RNA extraction kit. Reverse transcription was performed with the SuperScript First-Strand Synthesis System (Invitrogen). cDNA amounts were analyzed by RT-PCR with Taqman System (Applied Biosystems). Each sample was assayed in triplicate for HA together with the internal reference, HPRT, using Taqman Universal PCR Master Mix and ABI Prism 7700 Sequence Detection System (Applied Biosystems). The relative HA mRNA frequencies were determined by normalization to HPRT. cDNA from $\mathrm{BALB} / \mathrm{c}$ splenocytes was used as a negative control. The 
primer sequences for HA were $5^{\prime}$-CGCCGGATGGCTCTTG-3' (forward) and 5'-ACAATGTAGGACCATGATCTCACTG-3' (reverse). The HA-specific probe sequence was $5^{\prime}$ 6FAMAAACCCAGAATGCGACCCACTGCTTTAMRA$3^{\prime}$. For in vitro cell culture assay, $2 \times 10^{6}$ cells per sample were added to 6-well plates with $5 \mathrm{~mL}$ of the G418 selection media, and cell growth was monitored for 7 days.

2.7. Flow Cytometry. Lymphocyte suspensions were prepared as described above and washed with FACS buffer, and $1 \times 10^{6}$ cells per samples were stained in 20 min with a standard procedure for three-color flow cytometry. Fifty thousand gated events were collected on a FACScan (Becton Dickinson, San Jose, CA) and $\mathrm{CD} 4^{+} \mathrm{CD} 44^{+}$Thyl.1 ${ }^{+} \mathrm{T}$ cells were analyzed with CellQuest software (Becton Dickinson). Background staining of a specified area from control $\mathrm{BALB} / \mathrm{c}$ mice was usually lesser $0.01 \%$.

2.8. DNA-HA Vaccination. A recombinant vaccinia virus encoding HA antigen from the 1934 PR8 strain of influenza virus was kindly provided by Prof. H. Levitsky. Virus HAvaccine (HA-Vac) was expanded on $\mathrm{HU}_{-} \mathrm{TK}^{-}$cells in presence of 5-bromo-2'-deoxyuridine (Sigma) at $25 \mu \mathrm{g} / \mathrm{mL}$. Virus was purified from the cellular lysate by sucrose banding and tittered by plaque assay on BSC- 1 cells. HA-Vac $\left(10^{7} \mathrm{PFU}\right)$ was delivered intraperitoneally (i.p.) in $0.1 \mathrm{~mL}$ HBSS as described [20] on day 15 after the adoptive transfer.

\subsection{In Vitro Cell Cultures for FACS, Proliferative, and ELISA} Assays. A total of $1 \times 10^{6}$ spleen cells or cervical lymphocytes extracted from recipient mice were incubated in round-bottom 96 -well plates with $10 \mu \mathrm{g} / \mathrm{mL}$ of MHC class II synthetic HA peptide. Cell cultures were harvested $72 \mathrm{~h}$ later and analyzed by FACS for $\mathrm{CD} 4^{+} \mathrm{CD} 44^{+}$Thyl.1 $1^{+} \mathrm{T}$ cells. For proliferative assay, the HA-stimulated cell cultures were pulsed finally $18 \mathrm{~h}$ with $1 \mu \mathrm{Ci}\left[{ }^{3} \mathrm{H}\right] \mathrm{TdR}$, and radioactivity was measured with a liquid scintillation counter as described [20]. For ELISA (IFN- $\gamma$ assay), the supernatants from HAstimulated cell cultures were harvested after $72 \mathrm{~h}$ incubation, and IFN- $\gamma$ concentrations were measured using the Quantikine M ELISA kit for murine IFN- $\gamma$ according to the manufacturer's instruction (R\&D Systems, Minneapolis, $\mathrm{MN})$. Individual data points of all three assays represent the mean of triplicate wells from three mice per group.

2.10. Statistical Analysis. A paired $t$-test was used to compare values where appropriate. The values of $P<0.05$ were considered statistically significant. Statistical analysis for mouse survival was performed using Kaplan-Meier survival and log-rank (Mantel-Cox) test. Statview 4.5 software (San Francisco, CA) was used for analysis.

\section{Results and Discussion}

3.1. A20HA Intracranial Growth and Survival Rate of A20HA Brain-Tumor-Bearing Mice. To assess the survival rate of A20HA brain-tumor-bearing mice, syngeneic BALB/c mice received i.c. injections of either $1 \times 10^{4}$ or $5 \times 10^{4}$ of A20HA cells. All mice that received $5 \times 10^{4}$ cells died within 23 days of the treatment with a median survival of 22.5 days (Figure 1(a); $P<0.05)$. Mice that received $1 \times 10^{4}$ cells died within 26 days with a median survival of 24 days $(P<0.05)$. Histological analysis of brains revealed that metastases were occasionally seen in the brain parenchyma distant from the injection site, and the tumor cells readily spread throughout the ventricles in the majority of animals (Figure 1(b)). The mice that showed such symptoms as untidiness, behavioral disorder, and weight loss (symptomatic mice) at the late stage of the tumor growth died in 1-2 days following these symptoms. Symptomatic mice had massive tumors at the injection site in contrast to mice which still had non of the above mentioned symptoms (asymptomatic mice). Rare infiltrates of lymphoid cells and massive necrotic areas, especially in symptomatic mice were also found (Figure $1(\mathrm{~b})$ ).

Thus, A20HA cells formed massive brain tumors in mice with $100 \%$ lethality within 23-26 days, and apparent metastasis outside the brain was not found by visual and microscopy study of all major organs and lymph nodes. This relates to other experimental and clinical observations concerning the preferentially localized growth of primary brain lymphomas [28-30]. However, A20HA cells were found in lymph nodes of the brain-tumor-bearing mice at the late stage of the tumor progression by means of RT-PCR (Figure 1(c); $P<0.05$ ) as well as by cell culture analysis (data not shown).

Next, we found the fatal depletion of lymphoid organs in symptomatic mice versus asymptomatic ones. In particular, spleens were reduced in size and cell numbers at least by 5 - to 10 -fold in symptomatic mice versus asymptomatic ones, and massive areas of lymphocyte depletion in spleen and lymph nodes were found (Figure 1(b)).

3.2. HA-Specific Activation and Depletion of $C D 4^{+} T$ Cells. In tumor-bearing mice depletion of activated antigen-specific $\mathrm{T}$ cells and development of anergy (diminution or lack of immunity to the antigen) are two general mechanisms of $\mathrm{T}$ cell tolerance to tumors [31-34]. The state of activation or anergy in Th cells can be monitored by quantitative dynamics of $\mathrm{CD} 4^{+} \mathrm{T}$ cells and by level of CD44 expression that is increased under the activation $[15,16,20,21]$.

In our experiments, cervical and inguinal lymph nodes as well as spleens from each mouse were analyzed by FACS with three-color staining for $\mathrm{CD} 4^{+} \mathrm{CD} 44^{+}$Thyl. $1^{+}$HA-specific $\mathrm{T}$ cells on days 2, 9, and 16 after the adoptive transfer (days 7, 14, and 21 after A20HA i.c. inoculation, resp.) (Figure 2). We observed that in contrast to tumor-free mice in the tumor-bearing mice both the percent of $\mathrm{CD} 4^{+}$Thyl. $1^{+} \mathrm{T}$ cells (Figures 2(a) and 2(b); $P<0.05$ ) and the level of CD44 expression by these cells (Figure 2(c); $P<0.05$ ) were increased in cervical lymph nodes as early as day 2 after the adoptive transfer, and the increasing of CD44 expression was kept until day 16. At the same time, significant depletion of the transferred $\mathrm{CD} 4^{+} \mathrm{T}$ cells in cervical lymph nodes was found on day 9 and especially on day $16(P<0.05)$. The same quantitative dynamics of $\mathrm{CD} 4^{+} \mathrm{T}$ cells was observed also in inguinal lymph nodes and spleens (data not shown). 

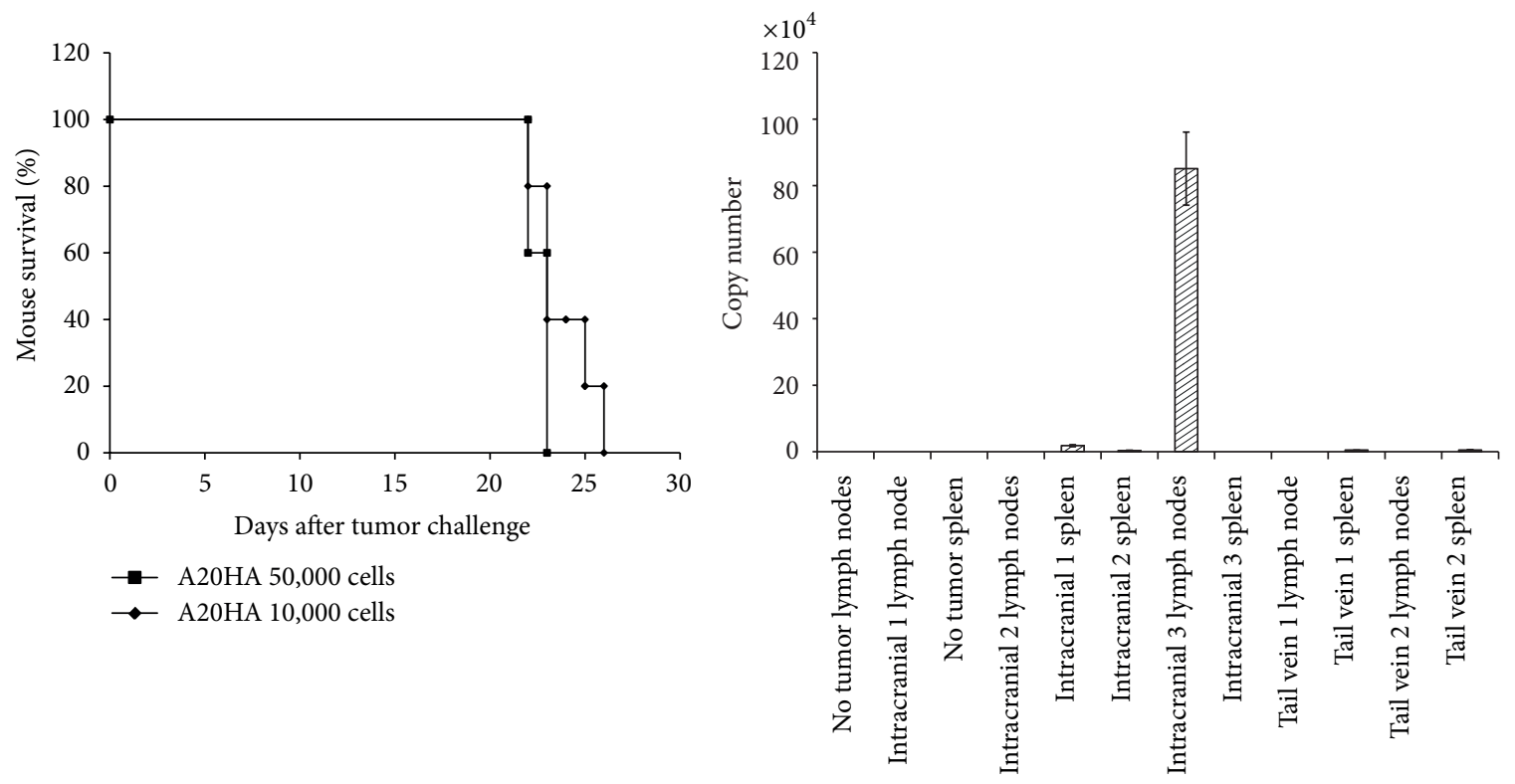

(a)

(c)
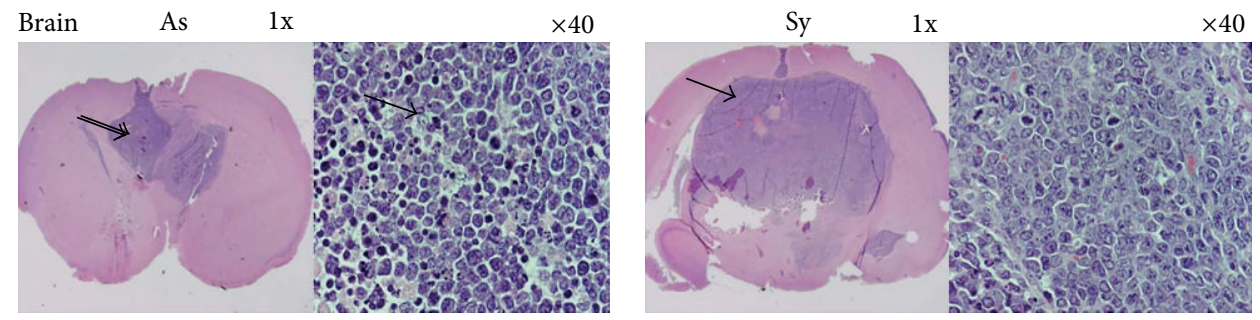

Spleen
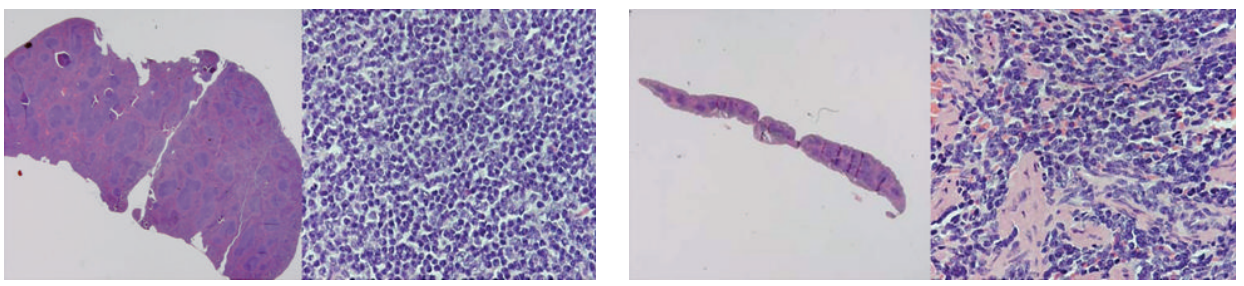

Lymph nodes
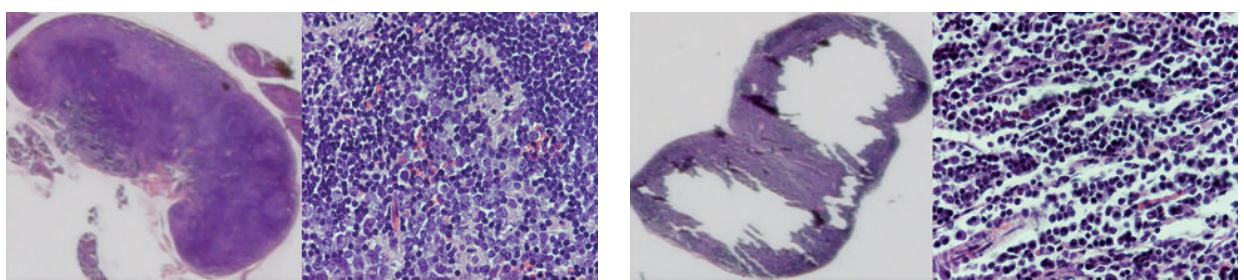

(b)

Figure 1: A20HA brain tumor growth in syngeneic BALB/c mice leads to fast death of mice and fatal depletion of spleens and lymph nodes in symptomatic mice. (a) Kaplan-Meier survival curve showing growth rates of A20HA B-cell lymphoma in brain after i.c. injection of 10,000 and 50,000 tumor cells ( $n=5$ in each group). A representative experiment among the three is shown. (b) Photomicrographs of eosin and hematoxylin stained coronal sections of the brains, spleens, and lymph nodes from (a) on day 21 after A20HA i.c. inoculation showing the forming of brain tumors (showed by arrows) and depletion of spleens and lymph nodes in asymptomatic (As) and symptomatic (Sy) mice that received 10,000 and 50,000 tumor cells, correspondingly. Magnifications $\times 1$ and $\times 40$. (c) RT-PCR of spleens and lymph nodes showing minor metastases of A20HA cells in lymph nodes on day 14 after i.c. A20HA injection (50,000 cells). Three individual mice in each group were analyzed. $P<0.05$. 

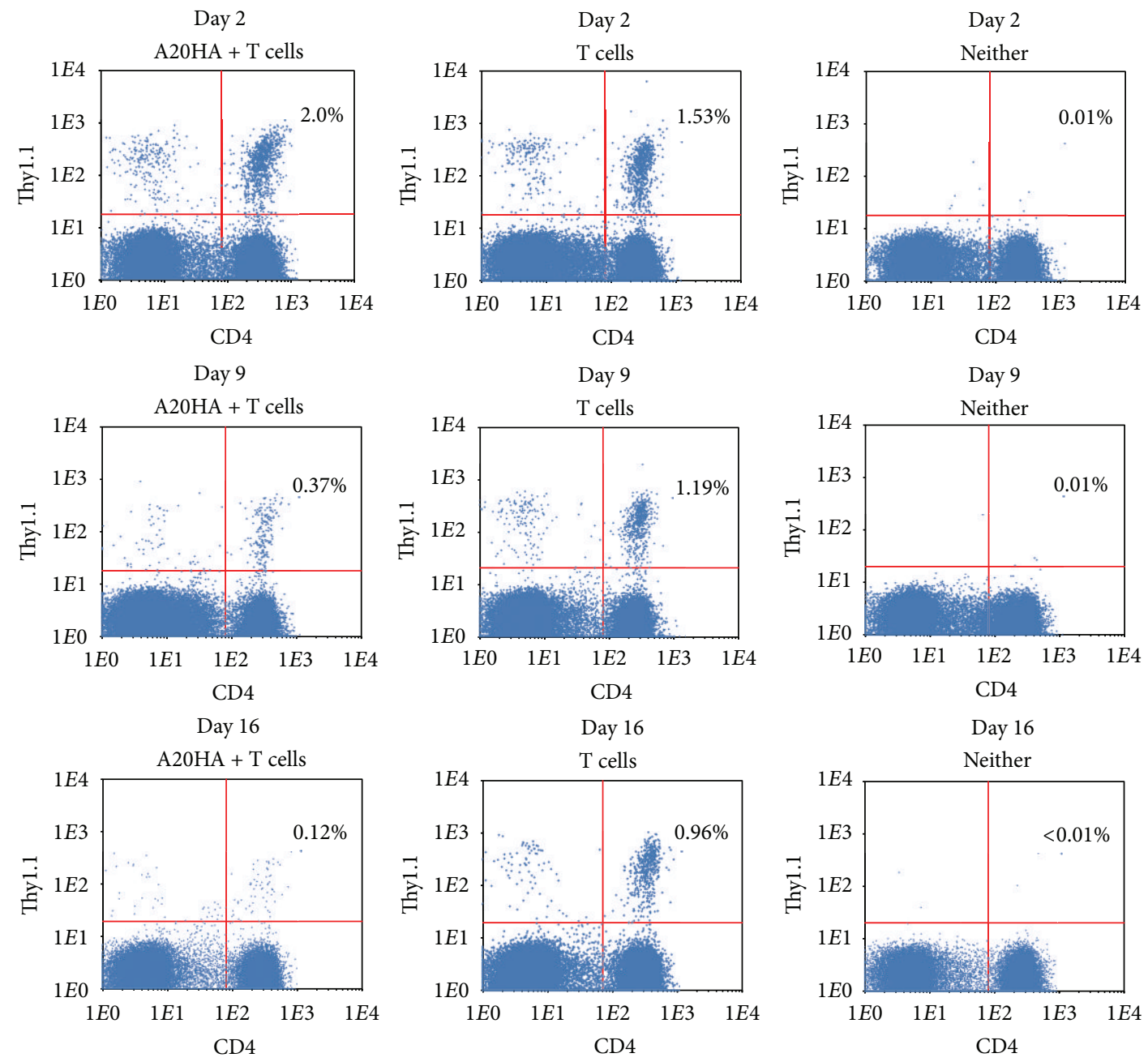

(a)

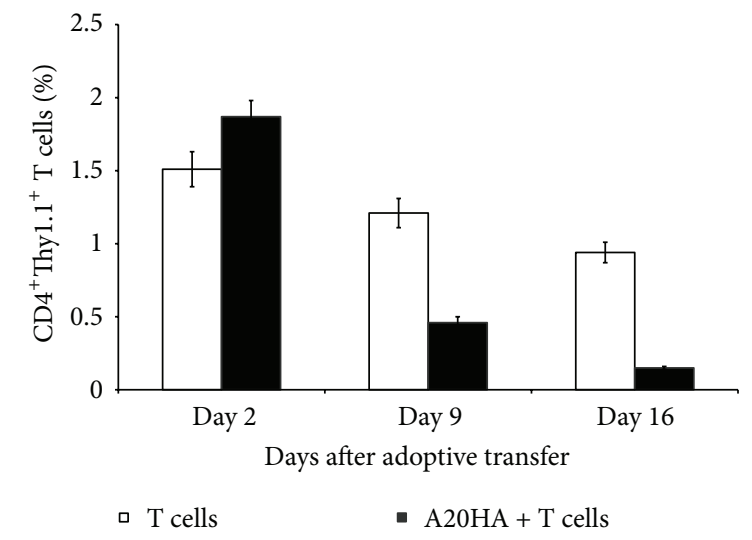

(b)

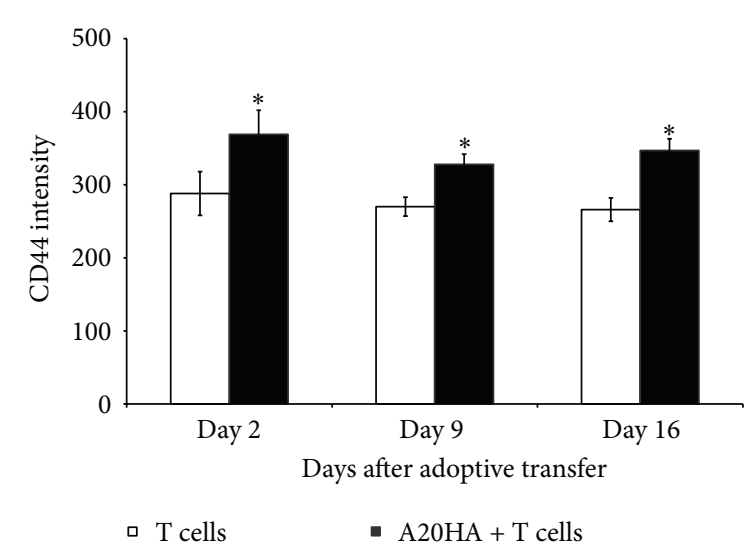

(c)

FIGURE 2: Adoptively transferred HA-specific $\mathrm{CD} 4^{+}$Thyl.1 $1^{+} \mathrm{T}$ cells demonstrate early activation and following depletion in cervical lymph nodes of A20HA brain tumor-bearing mice. ((a), (b), (c)) Flow cytometry of CD $4^{+}$Thyl. $1^{+} \mathrm{CD} 44^{+} \mathrm{T}$ cells from cervical lymph nodes on days 2, 9, and 16 after adoptive transfer. HA-specific CD4 ${ }^{+}$Thyl. $1^{+}$T cells were injected i.v. into A20HA brain tumor-bearing mice 5 days after i.c. tumor inoculation (A20HA + T cells; left column) and tumor-free control mice (T cells; middle column). Naive mice represented a negative control (Neither; right column). Each group included three mice. Cervical lymph nodes were analyzed individually from each mouse by three-color FACS assay. A representative experiment among three equivalents is shown. (a) Dot plots show gated HA-specific CD4 $4^{+}$Thyl. $1^{+}$ T cells (upper right quadrants; numbers in the quadrants indicate percent cells in each). Bars show (b) percent of HA-specific CD $4^{+}$Thy- $1.1^{+}$ $\mathrm{T}$ cells and (c) intensity of CD44 expression in the gated population of CD4 ${ }^{+}$Thy- $1.1^{+} \mathrm{T}$ cells. Data are represented as the mean $\pm \mathrm{SD}, n=3$. ${ }^{*} P<0.05$. 

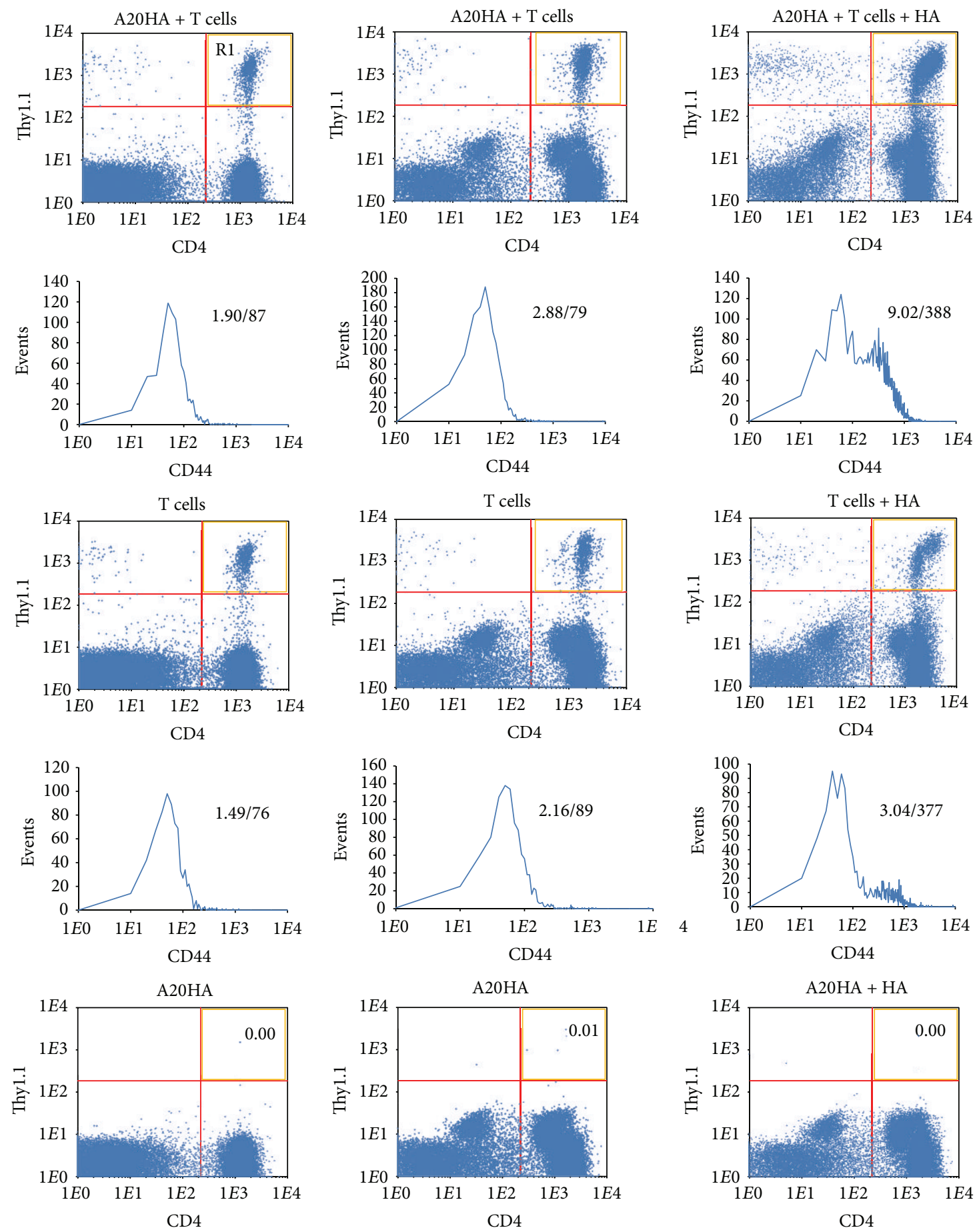

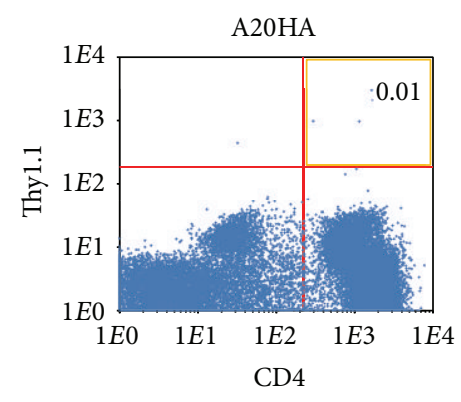

(b) In vitro

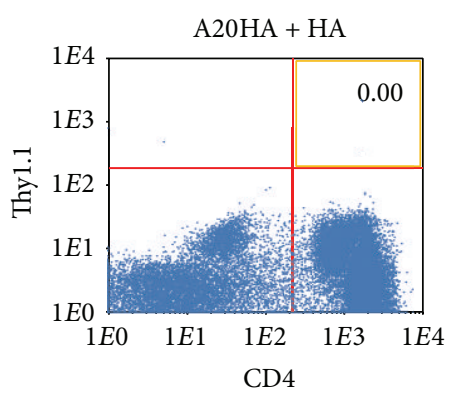

(c) In vitro

FIgure 3: HA-specific CD4 ${ }^{+}$Thyl. $1^{+} \mathrm{T}$ cells from cervical lymph nodes of A20HA brain tumor-bearing mice show increased response to restimulation in vitro with MHC class II synthetic HA peptide. ((a), (b), (c)) Flow cytometry of CD $4^{+}$Thyl. $1^{+} \mathrm{CD} 44^{+} \mathrm{T}^{-}$cells from cervical lymph nodes on day 2 after adoptive transfer. HA-specific $\mathrm{CD} 4^{+}$Thyl. $1^{+}$T cells were injected i.v. into A20HA brain tumor-bearing mice 5 days after i.c. tumor inoculation (A20HA + T cells; dot plots in the upper row) and a tumor-free control group (T cells; dot plots in the middle row). A20HA brain tumor-bearing mice in the absence of HA-specific $\mathrm{CD} 4{ }^{+}$Thyl.1 $1^{+} \mathrm{T}$ cells represented a negative control (A20HA; dot plots in the lower row). Cervical lymph nodes were pooled and analyzed for $\mathrm{CD} 4^{+}$Thyl. $1^{+} \mathrm{CD} 44^{+} \mathrm{T}$ cells (a) before incubation (in vivo column; right upper quadrants) and ((b), (c)) after $72 \mathrm{~h}$ incubation in vitro in triplicates (b) without (in vitro column; right upper quadrants) and (c) with (in vitro column; right upper quadrants) HA peptide. Histograms under the dot plots show the level of CD44 expression in the gated populations of $\mathrm{CD} 4^{+}$Thy-1.1 $1^{+} \mathrm{T}$ cells (shown in the right upper quadrants). Numbers above histograms indicate percent of gated $\mathrm{CD} 4^{+} \mathrm{Thy}-1.1^{+} \mathrm{T}$ cells in the designed dot plots (left numbers) and intensity of CD44 expression by these cells (right numbers). One representative experiment of equivalent two is shown. 

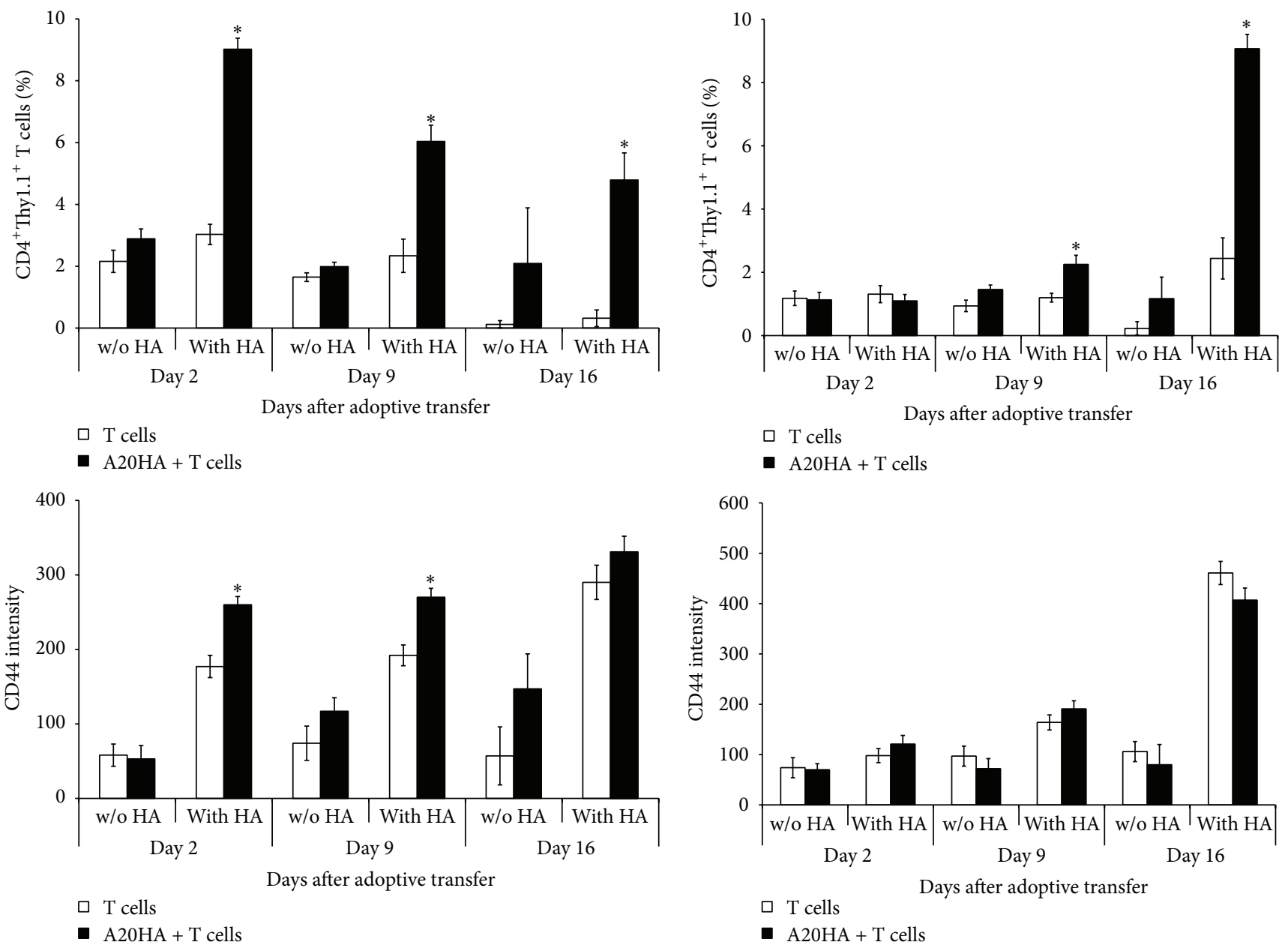

(a)

(b)

FIGURE 4: Response of HA-specific $\mathrm{CD} 4^{+}$Thy- $1.1^{+} \mathrm{T}$ cells from cervical lymph nodes of A20HA brain tumor-bearing mice to HA peptide in vitro is reduced in process of the tumor progression and controversial to response of $\mathrm{CD} 4^{+} \mathrm{T}$ cells from spleen. ((a), (b)) Percent of CD $4^{+}$Thy$1.1^{+} \mathrm{T}$ cells (upper) and intensity of CD44 expression (lower) by cells isolated from (a) cervical lymph nodes and (b) spleens on days 2, 9, and 16 after the adoptive transfer. HA-specific CD $4^{+}$Thyl. $1^{+} \mathrm{T}$ cells were injected i.v. into A20HA brain tumor-bearing mice 5 days after i.c. tumor inoculation (A20HA + T cells) and tumor-free control mice (T cells). A20HA brain tumor-bearing mice in the absence of HA-specific $\mathrm{CD}^{+}$Thyl. $1^{+} \mathrm{T}$ cells represented a negative control (background staining of a specified area was lesser than $0.01 \%$; data not shown). Cervical lymph nodes and spleens were pooled and analyzed by FACS for CD $4^{+}$Thyl. $1^{+} \mathrm{CD} 44^{+} \mathrm{T}$ cells before incubation and after $72 \mathrm{~h}$ incubation without (w/o) and with HA peptide. FACS data are presented as a percent of double positive cells, CD4 versus Thyl.1, and the level of CD44 expression in the $\mathrm{CD} 4{ }^{+}$Thyl. $1^{+}$T-cell population. One representative experiment of equivalent two is shown. ${ }^{*} \mathrm{P}<0.05$.

\subsection{Response of HA-Specific CD $4^{+}$T Cells to Restimulation} with HA Peptide In Vitro. The response of adoptively transferred HA-specific $\mathrm{CD}^{+}{ }^{+} \mathrm{T}$ cells to restimulation in vitro with MHC class II synthetic HA peptide that is valuable for analysis the activation or anergic state in adoptively transferred T cells $[20,21]$ was evaluated. Mice were sacrificed on days 2, 9, and 16 following the adoptive transfer, and pools of lymphocytes from cervical and inguinal lymph nodes and spleens were analyzed by FACS before and after 3day incubation with or without HA peptide. Proliferative response to $\mathrm{HA}$ peptide and levels of IFN- $\gamma$ production in vitro were also measured in the samples as indexes of activation versus anergy $[20,21]$.

In strong correlation with experiments above, the cervical HA-specific $\mathrm{CD}^{+} \mathrm{T}$ cells were already specifically activated in vivo on day 2 after the adoptive transfer to A20HA brain tumor-bearing mice (Figure 3(a); $P<0.05$ ). The cell incubation with HA peptide in vitro significantly increased both the expression of CD44 and number of HA-specific $\mathrm{CD}^{+}{ }^{+} \mathrm{T}$ cells (Figure 3(c); $P<0.05$ ). The declined response to the HA peptide was observed on days 9 and 16 after the adoptive transfer (Figure 4(a), upper; $P<0.05$ ), though this response was still very strong until day $16(P<0.05)$. In contrast, increasing of CD44 expression in response to in vitro HA stimulation was even higher on day 16 than on days 2 and 9 (Figure 4(a), lower; $P<0.05$ ). In control group of mice which were not injected with the tumor cells, response to HA peptide evaluated by changing of HA-specific $\mathrm{CD} 4^{+} \mathrm{T}$-cell number was comparatively low, and increasing of CD44 expression was lesser than in the tumor-bearing 


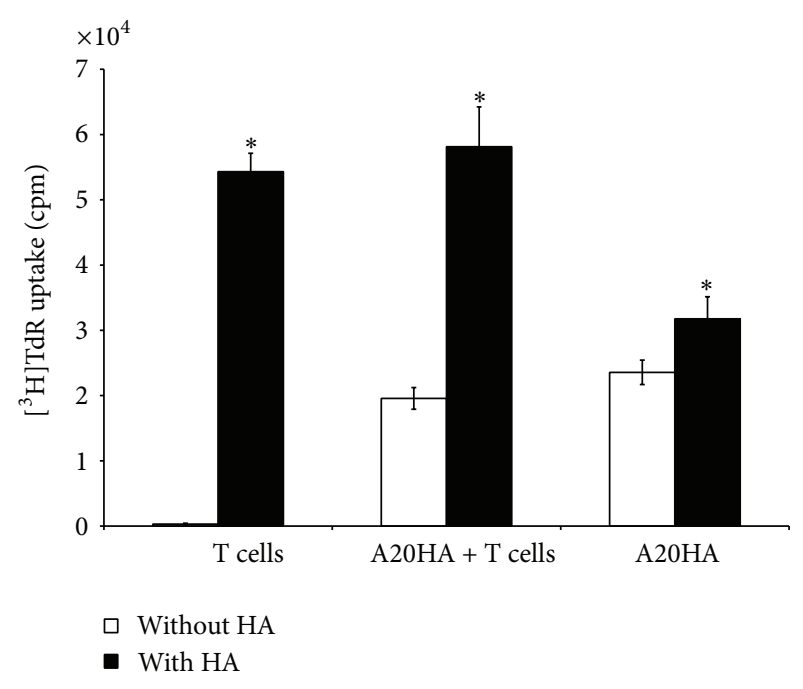

(a)

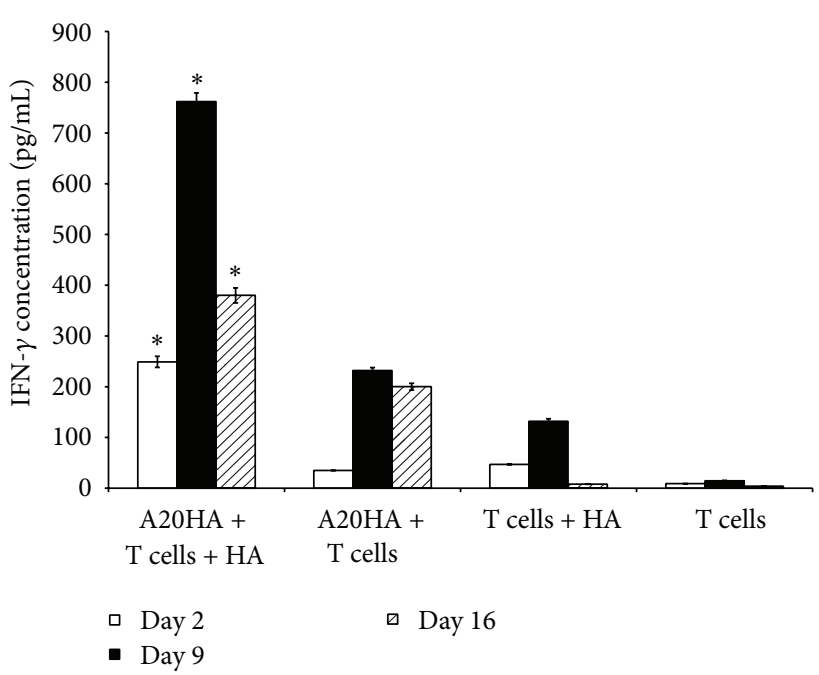

(b)

FIGURE 5: Proliferative response and production of IFN- $\gamma$ by HA-specific CD4 ${ }^{+}$Thyl. $1^{+} \mathrm{T}$ cells from A20HA brain tumor-bearing mice demonstrate nonanergic status of a part the adoptively transferred Th cells. HA-specific $\mathrm{CD} 4^{+}$Thyl. $1^{+} \mathrm{T}$ cells were injected i.v. on day 5 after i.c. tumor inoculation into A20HA brain tumor-bearing mice (A20HA + T cells) and tumor-free control mice (T cells). A20HA brain tumorbearing mice in the absence of HA-specific CD4 ${ }^{+}$Thyl. $1^{+} \mathrm{T}$ cells represented a negative control (A20HA). Spleens and cervical lymph nodes were pooled and analyzed after $72 \mathrm{~h}$ incubation with or without HA peptide in triplicates. (a) Proliferative response of HA-specific CD $4^{+}$ $\mathrm{T}$ cells from spleens of A20HA brain tumor-bearing mice to restimulation in vitro with HA peptide is not reduced. Cell proliferation was measured by $\left[{ }^{3} \mathrm{H}\right] \mathrm{TdR}$ incorporation on day 16 after the adoptive transfer. (b) Production of IFN- $\gamma$ by HA-specific CD $4^{+}$T cells from cervical lymph nodes of A20HA brain tumor-bearing mice induced by restimulation in vitro with HA peptide is maximal on day 9 and reduced on day 16 after the adoptive transfer. IFN- $\gamma$ concentration was measured by ELISA. Data are represented as the mean $\pm \mathrm{SD}, n=3$. ${ }^{*} P<0.05$.

mice (Figure 3, middle row; $P>0.05$ and Figure 4(a); $P<0.05)$. In contrast to cervical lymph nodes, significant increase in both the percent of $\mathrm{CD} 4^{+}$Thy- $1.1^{+} \mathrm{T}$ cells and the expression of CD44 in spleen was observed only on day 16 after the adoptive transfer $(P<0.05)$, and the number of $\mathrm{CD} 4^{+}$Thy-1.1 $1^{+} \mathrm{T}$ cells was equivalent to that observed in cervical lymph nodes on day 2 (Figure 4(b); $P>0.05$ ).

Proliferative response of HA-specific $\mathrm{CD}^{+}{ }^{+} \mathrm{T}$ cells isolated on day 16 after the adoptive transfer from spleens of A20HA brain tumor-bearing mice to HA peptide in vitro was comparable with proliferative response of spleen cells from tumor-free mice that were injected with TCR transgenic T cells (Figure 5(a); $P>0.05$ ) suggesting their nonanergic status. In contrast, proliferative response of spleen cells from A20HA brain tumor-bearing mice in absence of the TCR transgenic $\mathrm{T}$ cells was significantly lower $(P<0.05)$ which shows the specificity of A20HA stimulated activation of HAspecific $\mathrm{CD} 4^{+} \mathrm{T}$ cells in vivo and their specific restimulation with HA peptide in vitro.

The maximal level of IFN- $\gamma$ production by HA-specific $\mathrm{CD} 4^{+} \mathrm{T}$ cells isolated from cervical lymph nodes the brain tumor-bearing mice was found on day 9 after the adoptive transfer both in presence of and without HA peptide (Figure 5(b)). However, the cells isolated from A20HA brain tumor-bearing mice on day 2 were already able to produce IFN- $\gamma$ at the additional stimulation with HA peptide in vitro. IFN- $\gamma$ production was impaired but still significant on day 16 (Figure 5(b); $P<0.05$ ).
These data collectively show that the adoptively transferred HA-specific $\mathrm{CD}^{+}{ }^{+} \mathrm{T}$ cells become activated already on day 2 after the adoptive transfer to A20HA brain tumorbearing mice and reach the maximal activation on day 9 which correlates with increased IFN- $\gamma$ production. At the late stage of the tumor progression significant depletion of the transferred $\mathrm{CD}^{+}{ }^{+} \mathrm{T}$ cells (day 16) correlates with impaired level of IFN- $\gamma$ production demonstrating the development of tumor-specific anergy. However, a sufficient part of functionally active tumor-specific $\mathrm{CD} 4^{+} \mathrm{T}$ cells is still kept (especially in spleen) even at late stages of A20HA brain tumor progression demonstrating their nonanergic status.

\subsection{Response of HA-Specific CD $4^{+} T$ Cells to HA Vaccination} In Vivo and Restimulation with HA Peptide In Vitro in Symptomatic and Asymptomatic Mice. Additionally, the state of anergy or activation in the adoptively transferred HAspecific $\mathrm{CD} 4^{+} \mathrm{T}$ cells was analyzed by their challenging with recombinant HA vaccinia virus (HA-Vac) in vivo. HA-Vac was injected on day 15 after the adoptive transfer and 3 days later (day 23 after A20HA inoculation) lymphocytes from cervical lymph nodes and spleens were analyzed by FACS for $\mathrm{CD} 4^{+} \mathrm{CD} 44^{+}$Thy-1.1 $1^{+}$HA-specific T cells separately in symptomatic and asymptomatic mice where it was possible. Though, the development of strong anergy in adoptively transferred $\mathrm{T}$ cells to this time of the tumor progression could be expected, the significant amount of $\mathrm{CD} 4^{+} \mathrm{T}$ cells 

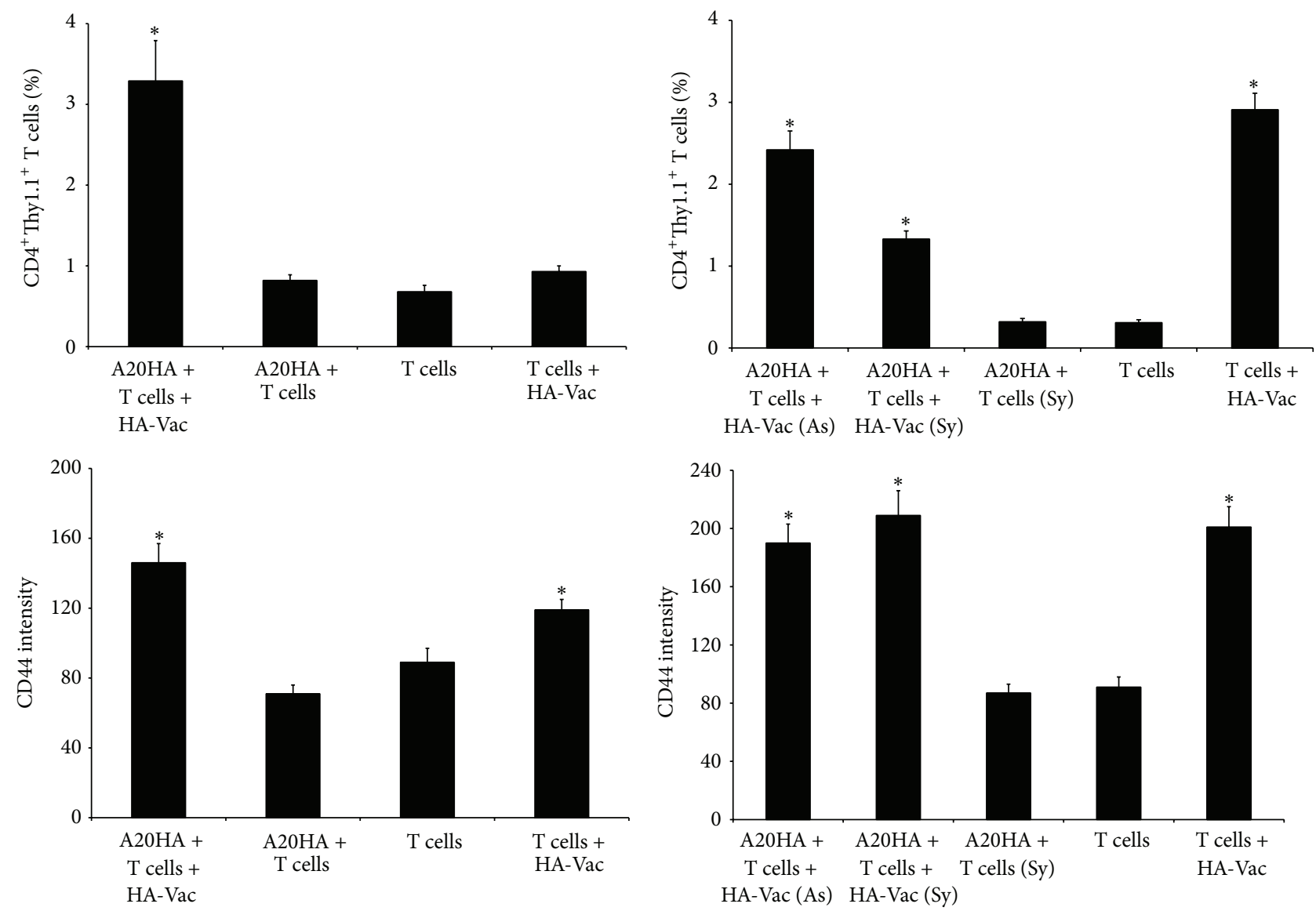

(a)

(b)

FIGURE 6: Virus HA vaccination at late stages of A20HA brain tumor progression stimulates activation of residual HA-specific CD $4^{+}$T cells in vivo. ((a), (b)) Percent of CD $4^{+}$Thy-1.1 $1^{+}$T cells (upper) and intensity of CD44 expression (lower) by cells isolated from (a) cervical lymph nodes and (b) spleens from separated asymptomatic (As) and symptomatic (Sy) mice on day 18 after the adoptive transfer. HA-specific CD4 $4^{+}$Thyl.1 ${ }^{+}$ T cells were injected i.v. to A20HA brain tumor-bearing mice on day 5 after i.c. tumor inoculation. Virus HA-Vac was delivered i.p. on day 15 after the adoptive transfer. Individual cervical lymph nodes and spleens of asymptomatic and symptomatic mice (three mice per group) were analyzed by FACS for $\mathrm{CD}_{4}^{+} \mathrm{CD} 44^{+}$Thyl.1 $1^{+} \mathrm{T}$ cells. A20HA + T cells + HA-Vac, mice that received A20HA tumor cells, HA-specific $\mathrm{CD} 4^{+}$Thyl. $1^{+} \mathrm{T}$ cells and virus HA-Vac; A20HA + T cells, mice that received A20HA tumor cells and HA-specific CD $4^{+}$Thyl. $1^{+} \mathrm{T}$ cells; $\mathrm{T}$ cells + HA-Vac, mice that received HA-specific CD $4^{+}$Thyl. $1^{+}$T cells and virus HA-Vac; T cells, mice that received only HA-specific CD4 ${ }^{+}$Thyl. $1^{+}$ T cells. Data are represented as the mean $\pm \mathrm{SD}, n=3 .{ }^{*} P<0.05$.

responding to HA-Vac in cervical lymph nodes and spleens of asymptomatic mice was found (Figures 6(a) and 6(b), upper; $P<0.05)$, and the level of T-cell activation (CD44 expression) was comparable to mice without A20HA brain tumor (Figures 6(a) and 6(b), lower; $P>0.05$ ). However, the symptomatic mice showed reduced response to in vivo HA-Vac measured by percentage change of CD $4^{+}$Thy $-1.1^{+} \mathrm{T}$ cells in spleen compared to asymptomatic mice (Figure 6(b), upper; $P<0.05)$. Oppositely, a level of CD44 expression in $\mathrm{CD} 4^{+}$Thy-1.1 $1^{+}$T-cell population was even higher in symptomatic mice versus asymptomatic ones (Figure 6(b), lower; $P<0.05)$. Though the late tumor-specific vaccination stimulated activation of remaining HA-specific $\mathrm{CD}^{+}{ }^{+} \mathrm{T}$ cell, any prolongation of survival in this group of mice versus control groups bearing A20HA brain tumor only or A20HA brain tumor together with transferred $\mathrm{CD} 4^{+} \mathrm{T}$ cells was not observed (data not shown).
Finally, the response of $\mathrm{HA}$-specific $\mathrm{CD}^{+}{ }^{+} \mathrm{T}$ cells from mice that received HA-Vac to restimulation with HA peptide in vitro was tested. Lymphocytes isolated from spleens of symptomatic mice on day 3 after HA vaccination were not able to respond to HA peptide in culture in vitro with increase of the percent of CD4 ${ }^{+}$Thy-1.1 $1^{+}$T cells (Figure 7(a), A20HA $+\mathrm{T}$ cells + HA-Vac, Sy; $P>0.05)$. Proliferative response (Figure $7(\mathrm{~b})$ ) and production of IFN- $\gamma$ (Figure $7(\mathrm{c})$ ) in this group of mice were also significantly reduced compared to asymptomatic mice $(P<0.05)$. In contrast, though $\mathrm{CD} 4^{+}$ T-cell response to HA peptide in vitro in absence of A20HA brain tumor was also insufficient (Figure 7(a), T cells + HAVac; $P>0.05)$, these cells were able to produce the significant quantity of IFN- $\gamma$ compared to all other groups of mice (Figure $7(\mathrm{c}) ; P<0.05)$. Thereby, these data show the state of strong anergy in tumor-specific $\mathrm{CD} 4^{+} \mathrm{T}$ cells in symptomatic mice versus asymptomatic mice. 


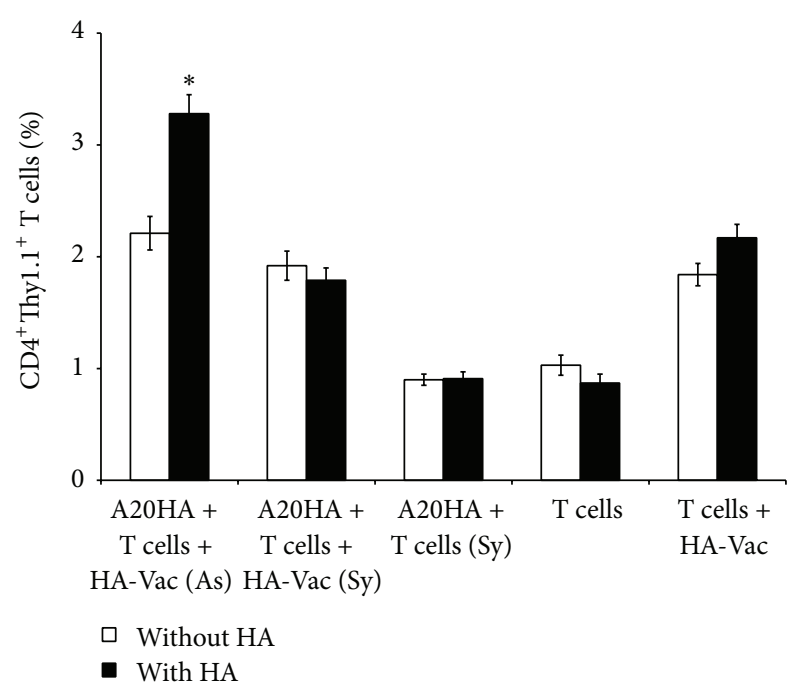

(a)

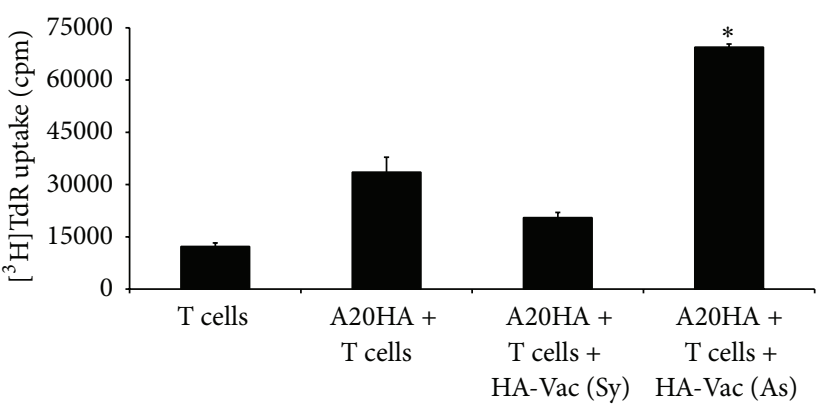

(b)

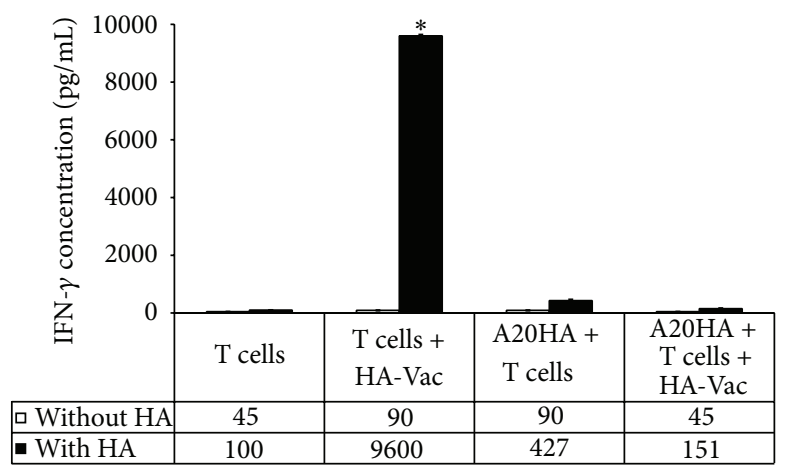

(c)

Figure 7: HA-specific $\mathrm{CD}^{+}{ }^{+} \mathrm{T}$ cells from spleen of symptomatic mice versus asymptomatic are refractory to restimulation with HA peptide in vitro after HA vaccination in vivo. (a) Percent of HA-specific CD $4^{+}$Thy- $1.1^{+} \mathrm{T}$ cells measured by FASC, (b) proliferative response measured by $\left[{ }^{3} \mathrm{H}\right] \mathrm{TdR}$ incorporation, and (c) concentration of IFN- $\gamma$ in the supernatants measured by ELISA on day 18 after the adoptive transfer. HA-specific $\mathrm{CD}^{+}{ }^{+}$Thyl.1 $1^{+}$T cells were injected i.v. into A20HA brain tumor-bearing mice on day 5 after i.c. tumor inoculation. Virus HA-Vac was delivered i.p. on day 15 after the adoptive transfer. Individual spleens from asymptomatic (As) and symptomatic (Sy) mice were isolated 3 days later, and cell cultures were analyzed after $72 \mathrm{~h}$ incubation with or without HA peptide in triplicate wells. A20HA + T cells + HA-Vac, mice that received A20HA tumor cells, HA-specific CD $4^{+}$Thyl. $1^{+}$T cells, and virus HA-Vac; A20HA + T cells, mice that received A20HA tumor cells and HA-specific CD $4^{+}$Thyl. $1^{+}$T cells; T cells + HA-Vac, mice that received HA-specific CD $4^{+}$Thyl.1 $1^{+}$T cells and virus HA-Vac; T cells, mice that received only HA-specific CD ${ }^{+}$Thyl. $1^{+}$T cells. Numbers under axis in (c) show IFN- $\gamma$ concentrations. Data are represented as the mean $\pm \mathrm{SD}, n=3 .{ }^{*} P<0.05$.

3.5. Migration of Activated HA-Specific $C D 4^{+}$T Cells into Brain. As known, activated $\mathrm{T}$ cells are capable of passing through the $\mathrm{BBB}$ and entering the CNS for antigen surveillance $[3,4]$. The ability of adoptively transferred CD $4^{+}$Thyl $11^{+} \mathrm{CD} 44^{+}$HA-specific $\mathrm{T}$ cells to penetrate into the brain and interact with the established A20HA brain tumor was evaluated by FACS on day 18 after the adoptive transfer and HA vaccination (Figure 8). The presence of a few number of highly activated (especially in group of HA-Vac mice) HA-specific CD $4^{+} \mathrm{CD} 44^{+}$Thy- $1.1^{+} \mathrm{T}$ cells into the brain of A20HA tumor-bearing mice as compared to non-HA-specific $\mathrm{CD} 4{ }^{+} \mathrm{CD} 44^{+}$Thy-1.1 ${ }^{-} \mathrm{T}$ cells was found (Figure $8(\mathrm{a}) ; P<0.05)$. Single lymphoid cells were found also on histological slides of the brains with A20HA tumors in the tumor growth area at the all investigated days after the adoptive transfer along with macrophage and glial cells that are normal components of brain (Figure 8(b), lower). In spite of presence of highly activated HA-specific transgenic $\mathrm{CD} 4^{+} \mathrm{T}$ cells into the brain, HA vaccination did not show any apparent influence on the tumor growth in this experimental model (Figure 8(b), upper).

Taken together, data presented here demonstrate that though BBB limits access of peripheral lymphocytes to the brain as well as tumor cells to periphery, A20HA brain tumor can induce both the state of activation and anergy in adoptively transferred HA-specific $\mathrm{CD}^{+} \mathrm{T}$ cells. These data suggest that the activation of HA-specific $\mathrm{T}$ cells may be a result of challenging these cells with tumor HA antigen 

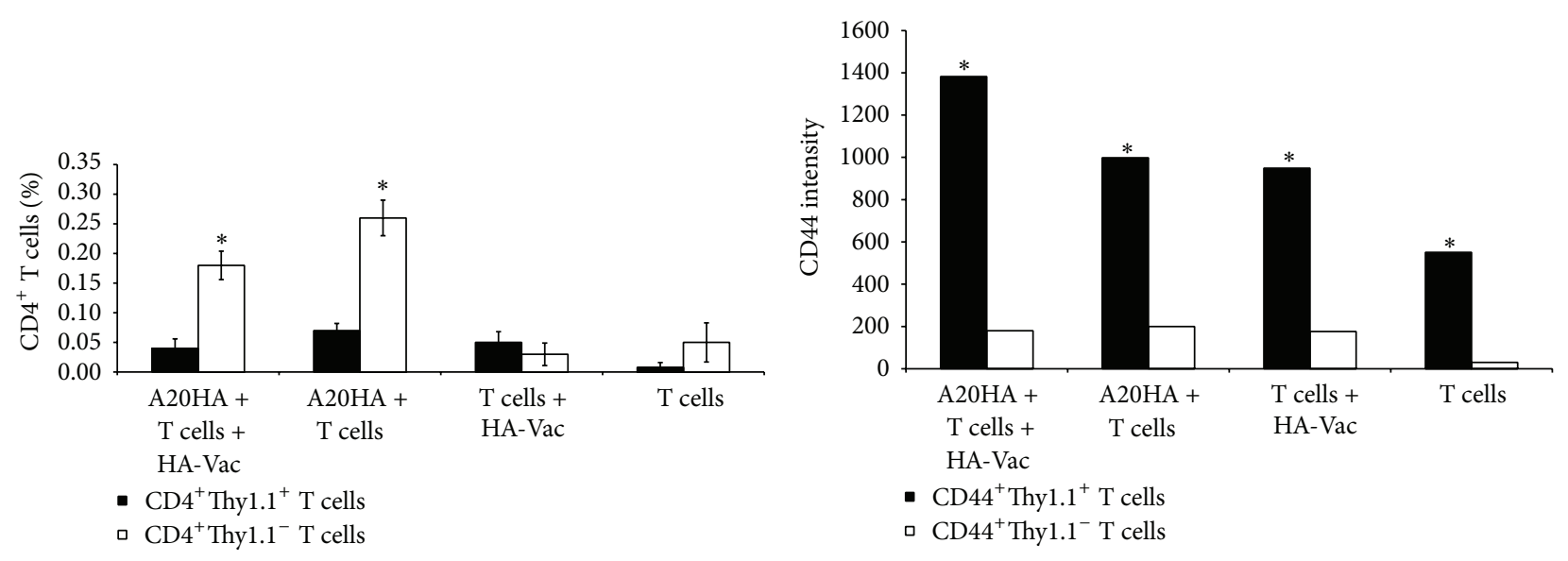

(a)

Day 2
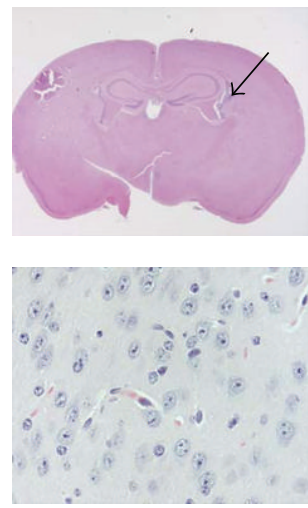

Day 9
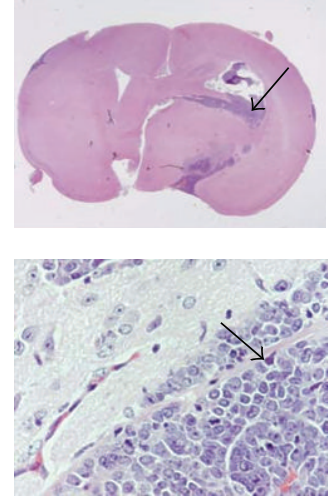

(b)
Day 18
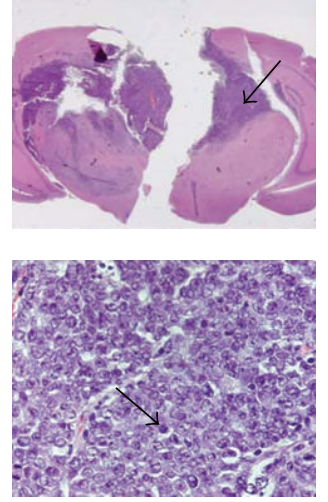

Figure 8: HA-specific activation stimulates migration of CD4 ${ }^{+} \mathrm{T}$ cells into the brain of A20HA brain tumor-bearing mice. (a) Percent (left bars) and CD44 intensity (right bars) of transgenic CD4 ${ }^{+}$Thyl. $1^{+} \mathrm{T}$ cells and nontransgenic $\mathrm{CD} 4^{+}$Thyl.1 $1^{-} \mathrm{T}$ cells from brains of A20HA brain tumor-bearing mice and A20HA tumor-free mice measured by FACS on day 18 after the adoptive transfer and HA vaccination. HA-specific $\mathrm{CD}^{+}{ }^{+}$Thyl. $1^{+}$T cells were injected i.v. on day 5 after A20HA i.c. inoculation, and virus HA-Vac was delivered i.p. at the same day. Brain pools of three mice in each group were analyzed by FACS 18 days later. A20HA + T cells + HA-Vac, mice that received A20HA tumor cells, HA-specific $\mathrm{CD}^{+}{ }^{+}$Thyl. $1^{+} \mathrm{T}$ cells, and HA-Vac; A20HA + T cells, mice that received A20HA tumor cells and HA-specific CD4 $4^{+}$Thyl. $1^{+}$T cells; T cells + HA-Vac, mice that received HA-specific CD $4^{+}$Thyl. $1^{+} \mathrm{T}$ cells and HA-Vac; T cells, mice that received only HA-specific CD $4^{+}$Thyl. $1^{+} \mathrm{T}$ cells. (b) Photomicrographs of eosin and hematoxylin stained coronal sections of the brains on days 2, 9, and 18 after the adoptive transfer showing growth dynamics of A20HA B-cell lymphoma in BALB/c mice that received HA-specific CD4 ${ }^{+}$T cells and HA-Vac on day 5 after A20HA i.c. inoculation. Magnifications $\times 1$ (upper row; arrows show the tumor areas) and $\times 40$ (lower row, arrows show single lymphocytes in the tumor areas). ${ }^{*} P<0.05$.

as outside the brain and within the brain. Although we did not observe significant infiltration of the brain tumors with foreign cells some numbers of the activated tumor-specific $\mathrm{T}$ cells could reach the brain. This possibility has been reported also with several experimental brain tumor models using local cytokine delivery that could support the growth of lymphocytes infiltrating a brain tumor and rescuing them from apoptosis [14, 35-37].

Other possibility for activation is capturing the soluble HA-antigen by dendritic cells outside the brain and presenting it to $\mathrm{CD}^{+} \mathrm{T}$ cells $[17,38]$. Though, it was reported, the serum of systemic A20HA tumor-bearing mice does not contain tumor-associated HA antigens even at a late stage of tumor progression [20], some observations demonstrated migration of tumor antigens from brain to periphery [39].
In contrast, the interaction with minor metastases that were found at least in cervical lymph nodes at late stages of A20HA growth in brain by means of RT-PCR and cell culturing for mostly of HA-specific $\mathrm{CD}^{+}{ }^{+} \mathrm{T}$ cells could lead to anergy because rejection of $\mathrm{MHC}$ class II tumor cells requires induction of tumor-encoded B7-1 and/or B7-2 costimulator molecules [40] and expression of these molecules by A20HA cells is low $[20,21]$. This point is supported also by other experiments with increase of immune response against A20 B-cell lymphoma transfected with a gene of B7 costimulator molecule [41, 42] and development of tumor-specific tolerance in systemic A20HA tumor models [20, 21, 24, 43].

Moreover, it was demonstrated that cross-presentation of HA-antigen by bone marrow dendritic cells is dominant mechanism of the development of tumor-specific tolerance in 
systemic A20HA tumor models and direct contact of $\mathrm{CD} 4^{+}$ $\mathrm{T}$ cells with tumor cells does not contribute significantly to that $[20,21,24]$. This mechanism of peripheral tolerization is not unique for lymphomas that express both MHC class I and MHC class II as well as costimulator B7-1 and B72 molecules and effective also for parenchyma self-antigens [31] and systemic tumors that express only MHC class I $[17,21,44]$. Moreover, regulatory $\mathrm{CD} 4^{+} \mathrm{CD} 25^{+} \mathrm{T}$ cells that appear in periphery and can reach a malignant brain also may contribute to the immunosuppression [45]. Thus, these mechanisms together may contribute to the development of HA-specific anergy in the used experimental model.

A number of studies also support a hypothesis that tumors evade immunological rejection by inducing the state of global immunosuppression at a late stage of a tumor progression $[20,21]$. This state has been clearly demonstrated in animals and patients with advanced tumors and is characterized by hyporesponsiveness to challenge with common recall antigen in vivo and diminished $\mathrm{T}$ cell function in vitro that correlates with specific alteration in $\mathrm{T}$ cell signal transduction pathways [44]. Tumor cells can produce several factors such as TGF- $\beta$, IL-10, and PG-E2 that can mediate this immunosuppression $[46,47]$. Also it was demonstrated recently that lactic acid which is extensively produced by major of tumors is potent immunosuppressant, metabolites of tryptophan cause potent immunosuppressive microenvironment in gliomas, and nitric oxides also are produced in tumors and cause immunosuppression [48-51]. High systemic levels of these compounds in organism during tumor last stage expansion could cause systemic toxic effects and lead to systemic immunosuppression as it was found in our experiments in symptomatic mice. We assume that this systemic immunosuppression may be a result of toxic stress syndrome, and corticosteroid hormones could play a key role in development of systemic immunosuppression. However, recent reports address inadequacy of murine models of human diseases, especially inflammatory diseases and cancer and extrapolation of these results to a human brain cancer should be done with caution.

\section{Abbreviations}

$\begin{array}{ll}\text { As: } & \text { Asymptomatic } \\ \text { BBB: } & \text { Blood brain barrier } \\ \text { CNS: } & \text { Central nervous system } \\ \text { HBSS: } & \text { Hanks buffered salt solution } \\ \text { HA: } & \text { Hemagglutinin } \\ \text { HA-Vac: } & \text { HA vaccinia virus } \\ \text { i.c.: } & \text { Intracranial } \\ \text { Sy: } & \text { Symptomatic } \\ \text { TCR: } & \text { T-cell receptor for antigen } \\ \text { Th: } & \text { T helper. }\end{array}$

\section{Conflict of Interests}

The authors declare no conflict of interests. The authors alone are responsible for the content of this paper.

\section{Acknowledgments}

This work was supported by grant from the W. W. Smith Charitable Trust Foundation, Johns Hopkins University, USA and from University "Ukraine", Ukraine. The authors thank Professor J. Hanes (Department of Chemical and Biomolecular Engineering, Johns Hopkins University), Professor H. Levitsky (Department of Oncology), and Professor H. Brem (Department of Neurosurgery) for help in designing of experiments and providing of critical materials and mice, Dr. B. Tyler (Department of Neurosurgery) for help with intracranial inoculations, and Dr. Ch. Long (Department of Chemical and Biomolecular Engineering) for help with RTPCR and cell culture metastasis experiments.

\section{References}

[1] I. Bechmann, I. Galea, and V. H. Perry, "What is the blood-brain barrier (not)?” Trends in Immunology, vol. 28, no. 1, pp. 5-11, 2007.

[2] H. Ando, M. Saio, N. Tamakawa et al., "Failure of B7.1-modified tumor to evoke full activation of $\mathrm{CD}^{+}$tumor-infiltrating lymphocytes in the central nervous system: prevention of parental tumor growth in the subcutaneous environment," Journal of Neurosurgery, vol. 97, no. 2, pp. 432-440, 2002.

[3] R. M. Ransohoff, P. Kivisäkk, and G. Kidd, "Three or more routes for leukocyte migration into the central nervous system," Nature Reviews Immunology, vol. 3, no. 7, pp. 569-581, 2003.

[4] W. F. Hickey, B. L. Hsu, and H. Kimura, "T-lymphocyte entry into the central nervous system," Journal of Neuroscience Research, vol. 28, no. 2, pp. 254-260, 1991.

[5] S. A. Riemersma, J. J. Oudejans, M. J. Vonk et al., "High numbers of tumour-infiltrating activated cytotoxic T lymphocytes, and frequent loss of HLA class I and II expression, are features of aggressive B cell lymphomas of the brain and testis," The Journal of Pathology, vol. 206, no. 3, pp. 328-336, 2005.

[6] M. G. Ewend, R. C. Thompson, R. Anderson et al., "Intracranial paracrine interleukin-2 therapy stimulates prolonged antitumor immunity that extends outside the Central Nervous System," The Journal of Immunotherapy, vol. 23, no. 4, pp. 438-448, 2000.

[7] H. R. Khan-Farooqi, R. M. Prins, and L. M. Liau, "Tumor immunology, immunomics and targeted immunotherapy for central nervous system malignancies," Neurological Research, vol. 27, no. 7, pp. 692-702, 2005.

[8] R. M. Prins, C. J. Shu, C. G. Radu et al., "Anti-tumor activity and trafficking of self, tumor-specific T cells against tumors located in the brain," Cancer Immunology, Immunotherapy, vol. 57, no. 9, pp. 1279-1289, 2008.

[9] C. M. Ryan, K. Staveley-O'Carroll, and T. D. Schell, "Combined anti-CD40 conditioning and well-timed immunization prolongs $\mathrm{CD}^{+} \mathrm{T}$ cell accumulation and control of established brain tumors," The Journal of Immunotherapy, vol. 31, no. 9, pp. 906-920, 2008.

[10] A. M. Tatum, L. M. Mylin, S. J. Bender et al., "CD8 ${ }^{+}$T cells targeting a single immunodominant epitope are sufficient for elimination of established SV40 T antigen-induced brain tumors," The Journal of Immunology, vol. 181, no. 6, pp. 44064417, 2008. 
[11] T.-G. Kim, C.-H. Kim, J.-S. Park et al., "Immunological factors relating to the antitumor effect of temozolomide chemoimmunotherapy in a murine glioma model," Clinical and Vaccine Immunology, vol. 17, no. 1, pp. 143-153, 2010.

[12] V. Siffrin, A. U. Brandt, H. Radbruch et al., "Differential immune cell dynamics in the CNS cause CD4 T cell compartmentalization," Brain, vol. 132, no. 5, pp. 1247-1258, 2009.

[13] H. Ando, M. Saio, N. Ohe et al., "B7.1 immunogene therapy effectively activates $\mathrm{CD} 4^{+}$tumor-infiltrating lymphocytes in the central nervous system in comparison with B7.2 gene therapy," International Journal of Oncology, vol. 20, no. 4, pp. 807-812, 2002.

[14] K. M. Giezeman-Smits, H. Okada, C. S. Brissette-Storkus et al., "Cytokine gene therapy of gliomas: induction of reactive $\mathrm{CD} 4^{+}$ $\mathrm{T}$ cells by interleukin-4-transfected 9L gliosarcoma is essential for protective immunity," Cancer Research, vol. 60, no. 9, pp. 2449-2457, 2000.

[15] K. Hung, R. Hayashi, A. Lafond-Walker, C. Lowenstein, D. Pardoll, and H. Levitsky, "The central role of $\mathrm{CD}^{+}{ }^{+} \mathrm{T}$ cells in the antitumor immune response," Journal of Experimental Medicine, vol. 188, pp. 2357-2368, 1998.

[16] H. I. Levitsky, J. Montgomery, M. Ahmadzadeh et al., "Immunization with granulocyte-macrophage colony-stimulating factor-transduced, but not B7-1-transduced, lymphoma cells primes idiotype-specific $\mathrm{T}$ cells and generates potent systemic antitumor immunity," The Journal of Immunology, vol. 156, no. 10, pp. 3858-3865, 1996.

[17] W. Kim and L. M. Liau, "Dendritic Cell Vaccines for Brain Tumors," Neurosurgery Clinics of North America, vol. 21, no. 1, pp. 139-157, 2010.

[18] L. A. Jones, L. T. Chin, D. L. Longo, and A. M. Kruisbeek, "Peripheral clonal elimination of functional T cells," Science, vol. 250, no. 4988, pp. 1726-1729, 1990.

[19] D. L. Mueller, M. K. Jenkins, and R. H. Schwartz, "Clonal expansion versus functional clonal inactivation: a costimulatory signalling pathway determines the outcome of $\mathrm{T}$ cell antigen receptor occupancy," Annual Review of Immunology, vol. 7, pp. 445-480, 1989.

[20] K. Staveley-O'Carroll, E. Sotomayor, J. Montgomery et al., "Induction of antigen-specific T cell anergy: an early event in the course of tumor progression," Proceedings of the National Academy of Sciences of the United States of America, vol. 95, no. 3, pp. 1178-1183, 1998.

[21] H. I. Levitsky, "Augmentation of host immune responses to cancer: overcoming the barrier of tumor antigen-specific ant Tcell tolerance," The Cancer Journal, vol. 6, no. 3, pp. S281-S290, 2000.

[22] F. Ramsdell, T. Lantz, and B. J. Fowlkes, "A nondeletional mechanism of thymic self tolerance," Science, vol. 246, no. 4933, pp. 1038-1041, 1989.

[23] Z. Lu, L. Yuan, X. Zhou, E. Sotomayor, H. I. Levitsky, and D. M. Pardoll, "CD40-independent pathways of T cell help for priming of $\mathrm{CD}^{+}$cytotoxic T lymphocytes," Journal of Experimental Medicine, vol. 191, no. 3, pp. 541-550, 2000.

[24] E. M. Sotomayor, I. Borrello, F.-M. Rattis et al., "Crosspresentation of tumor antigens by bone marrow-derived antigen-presenting cells is the dominant mechanism in the induction of T-cell tolerance during B-cell lymphoma progression," Blood, vol. 98, no. 4, pp. 1070-1077, 2001.

[25] M. Candolfi, K. M. Kroeger, A. K. M. G. Muhammad et al., "Gene therapy for brain cancer: combination therapies provide enhanced efficacy and safety," Current Gene Therapy, vol. 9, no. 5, pp. 409-421, 2009.

[26] D. A. Mitchell and J. H. Sampson, "Toward effective immunotherapy for the treatment of malignant brain tumors," Neurotherapeutics, vol. 6, no. 3, pp. 527-538, 2009.

[27] A. S. Wayne, C. M. Capitini, and C. L. MacKall, "Immunotherapy of childhood cancer: from biologic understanding to clinical application," Current Opinion in Pediatrics, vol. 22, no. 1, pp. 2-11, 2010.

[28] B. Al Bahrani, C. Henderson, and G. Delaney, "Primary central nervous system lymphoma and subcutaneous metastases," Journal of Neuro-Oncology, vol. 47, no. 2, pp. 141-144, 2000.

[29] R. Mohammad, Y. Abubakr, M. Dan et al., "Bcl-2 antisense oligonucleotides are effective against systemic but not central nervous system disease in severe combined immunodeficient mice bearing human $\mathrm{t}(14 ; 18)$ follicular lymphoma," Clinical Cancer Research, vol. 8, no. 4, pp. 1277-1283, 2002.

[30] M. Saini, M. Bellinzona, W. Weichhold, and M. Samii, "A new xenograft model of primary central nervous system lymphoma," The Journal of Neuro-Oncology, vol. 43, pp. 153-160, 1999.

[31] A. J. Adler, D. W. Marsh, G. S. Yochum et al., "CD4 ${ }^{+} \mathrm{T}$ cell tolerance to parenchymal self-antigens requires presentation by bone marrow-derived antigen-presenting cells," Journal of Experimental Medicine, vol. 187, no. 10, pp. 1555-1564, 1998.

[32] S. J. Antonia, M. Extermann, and R. A. Flavell, "Immunologic nonresponsiveness to tumors," Critical Reviews in Oncogenesis, vol. 9, no. 1, pp. 35-41, 1998.

[33] A. Mondino, A. Khoruts, and M. K. Jenkins, "The anatomy of T-cell activation and tolerance," Proceedings of the National Academy of Sciences of the United States of America, vol. 93, no. 6, pp. 2245-2252, 1996.

[34] C. B. Thompson and J. P. Allison, "The emerging role of CTLA-4 as an immune attenuator," Immunity, vol. 7, no. 4, pp. 445-450, 1997.

[35] J. Hanes, A. Sills, Z. Zhao et al., "Controlled local delivery of interleukin-2 by biodegradable polymers protects animals from experimental brain tumors and liver tumors," Pharmaceutical Research, vol. 18, no. 7, pp. 899-906, 2001.

[36] G. E. Plautz and S. Shu, "Adoptive immunotherapy of CNS malignancies," Cancer Chemotherapy and Biological Response Modifiers, vol. 19, pp. 327-338, 2001.

[37] P. Sampath, J. Hanes, F. DiMeco et al., "Paracrine immunotherapy with interleukin-2 and local chemotherapy is synergistic in the treatment of experimental brain tumors," Cancer Research, vol. 59, no. 9, pp. 2107-2114, 1999.

[38] D. L. Thomas, D. M. Kranz, and E. J. Roy, "Experimental manipulations of afferent immune responses influence efferent immune responses to brain tumors," Cancer Immunology, Immunotherapy, vol. 57, no. 9, pp. 1323-1333, 2008.

[39] S. Baskar, V. K. Clements, L. H. Glimcher, N. Nabavi, and S. Ostrand-Rosenberg, "Rejection of MHC class II-transfected tumor cells requires induction of tumor-encoded B7-1 and/or B7-2 costimulatory molecules," The Journal of Immunology, vol. 156, no. 10, pp. 3821-3827, 1996.

[40] Y.-J. Jang, S. Y. Nam, M.-S. Kim et al., "Simultaneous expression of allogenic class II MHC and B7.1 (CD80) molecules in A20 B-lymphoma cell line enhances tumor immunogenicity," Molecules and Cells, vol. 13, no. 1, pp. 130-136, 2002.

[41] E. Pizzoferrato, N. R. Chu, T. S. Hawley et al., "Enhanced immunogenicity of B cell lymphoma genetically engineered to express both B7-1 and interleukin-12," Human Gene Therapy, vol. 8 , no. 18 , pp. 2217-2228, 1997. 
[42] E. M. Sotomayor, I. Borrello, E. Tubb, J. P. Allison, and H. I. Levitsky, "In vivo blockade of CTLA-4 enhances the priming of responsive $\mathrm{T}$ cells but fails to prevent the induction of tumor antigen-specific tolerance," Proceedings of the National Academy of Sciences of the United States of America, vol. 96, no. 20, pp. 11476-11481, 1999.

[43] E. M. Sotomayor, I. Borrello, E. Tubb et al., "Conversion of tumor-specific $\mathrm{CD} 4{ }^{+} \mathrm{T}$-cell tolerance to $\mathrm{T}$-cell priming through in vivo ligation of cd40," Nature Medicine, vol. 5, no. 7, pp. 780787, 1999.

[44] H. Mizoguchi, J. J. O’Shea, D. L. Longo, C. M. Loeffler, D. W. McVicar, and A. C. Ochoa, "Alterations in signal transduction molecules in T lymphocytes from tumor-bearing mice," Science, vol. 258, no. 5089, pp. 1795-1798, 1992.

[45] J. F. M. Jacobs, A. J. Idema, K. F. Bol et al., "Regulatory T cells and the PD-L1/PD-1 pathway mediate immune suppression in malignant human brain tumors," Neuro-Oncology, vol. 11, no. 4, pp. 394-402, 2009.

[46] D. B. Constam, J. Philipp, U. V. Malipiero, P. Ten Dijke, M. Schachner, and A. Fontana, "Differential expression of transforming growth factor- $\beta 1,-\beta 2$, and $-\beta 3$ by glioblastoma cells, astrocytes, and microglia," The Journal of Immunology, vol. 148, no. 5, pp. 1404-1410, 1992.

[47] M. Hishii, T. Nitta, H. Ishida et al., "Human glioma-derived interleukin-10 inhibits antitumor immune responses in vitro," Neurosurgery, vol. 37, no. 6, pp. 1160-1167, 1995.

[48] E. Eruslanov, I. Daurkin, J. Vieweg, Y. Daaka, and S. Kusmartsev, "Aberrant PGE metabolism in bladder tumor microenvironment promotes immunosuppressive phenotype of tumorinfiltrating myeloid cells," International Immunopharmacology, vol. 11, no. 7, pp. 848-855, 2011.

[49] S. Y. Choi, C. C. Collins, P. W. Gout, and Y. Wang, "Cancergenerated lactic acid: a regulatory, immunosuppressive metabolite?” The Journal of Pathology, vol. 230, no. 4, pp. 350-355, 2013.

[50] M. Platten, M. Weller, and W. Wick, "Shaping the glioma immune microenvironment through tryptophan metabolism," CNS Oncology, vol. 1, no. 1, pp. 99-106, 2012.

[51] I. Hammami, J. Chen, F. Murschel, V. Bronte, G. de Crescenzo, and M. Jolicoeur, "Immunosuppressive activity enhances central carbon metabolism and bioenergetics in myeloid-derived suppressor cells in vitro models," BMC Cell Biology, vol. 4, pp. 13-18, 2012. 


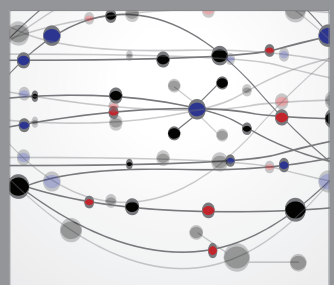

The Scientific World Journal
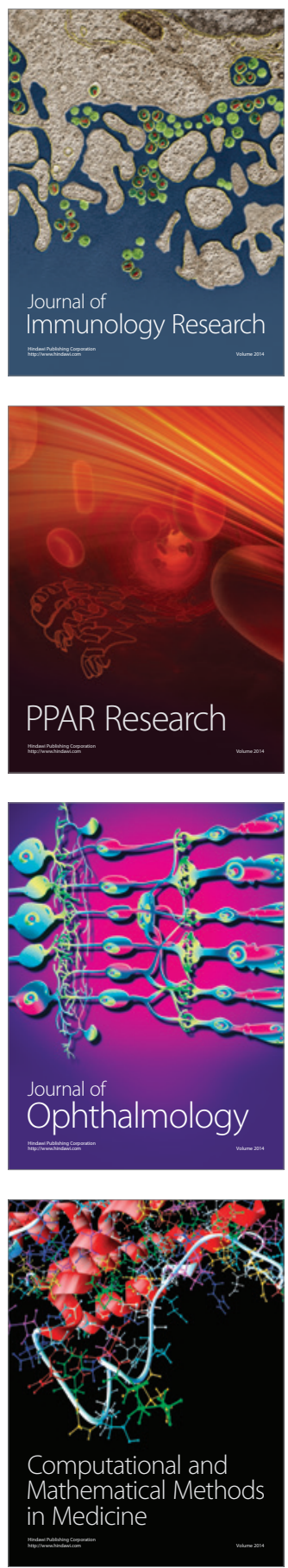

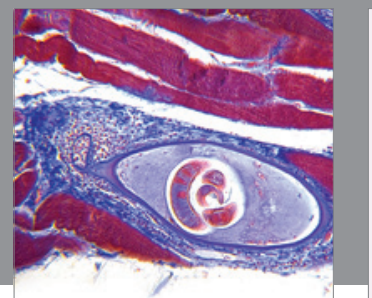

Gastroenterology

Research and Practice
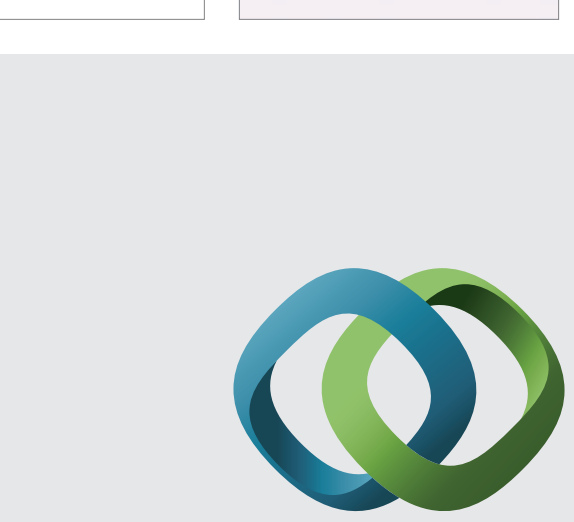

\section{Hindawi}

Submit your manuscripts at

http://www.hindawi.com
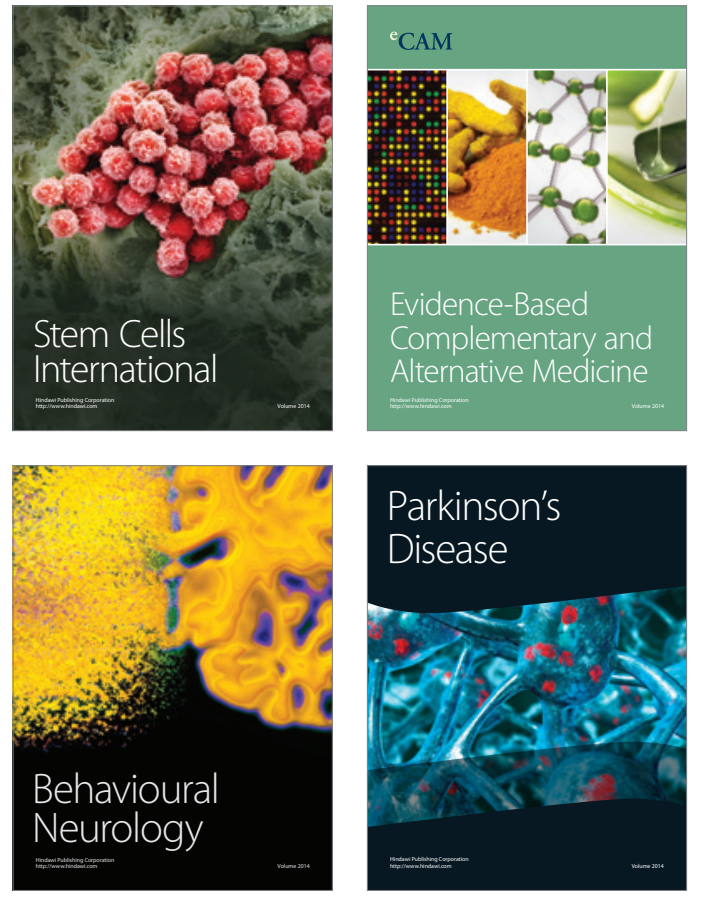
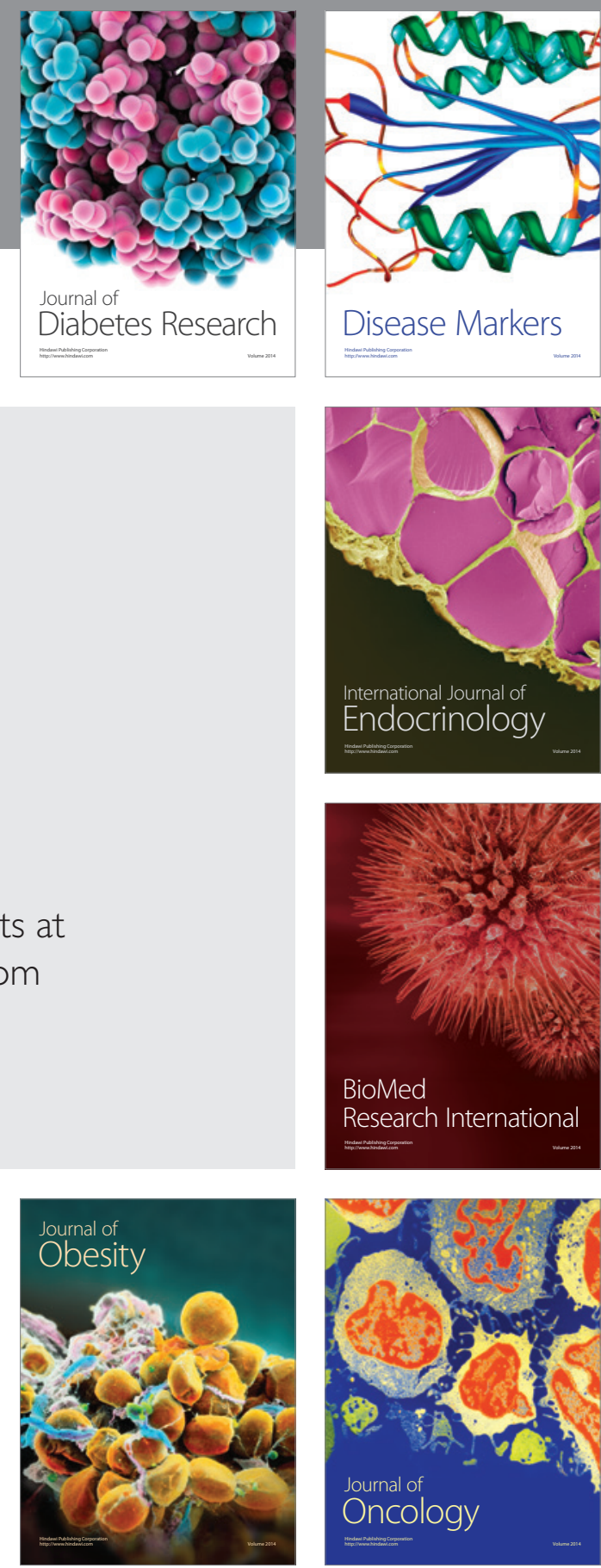

Disease Markers
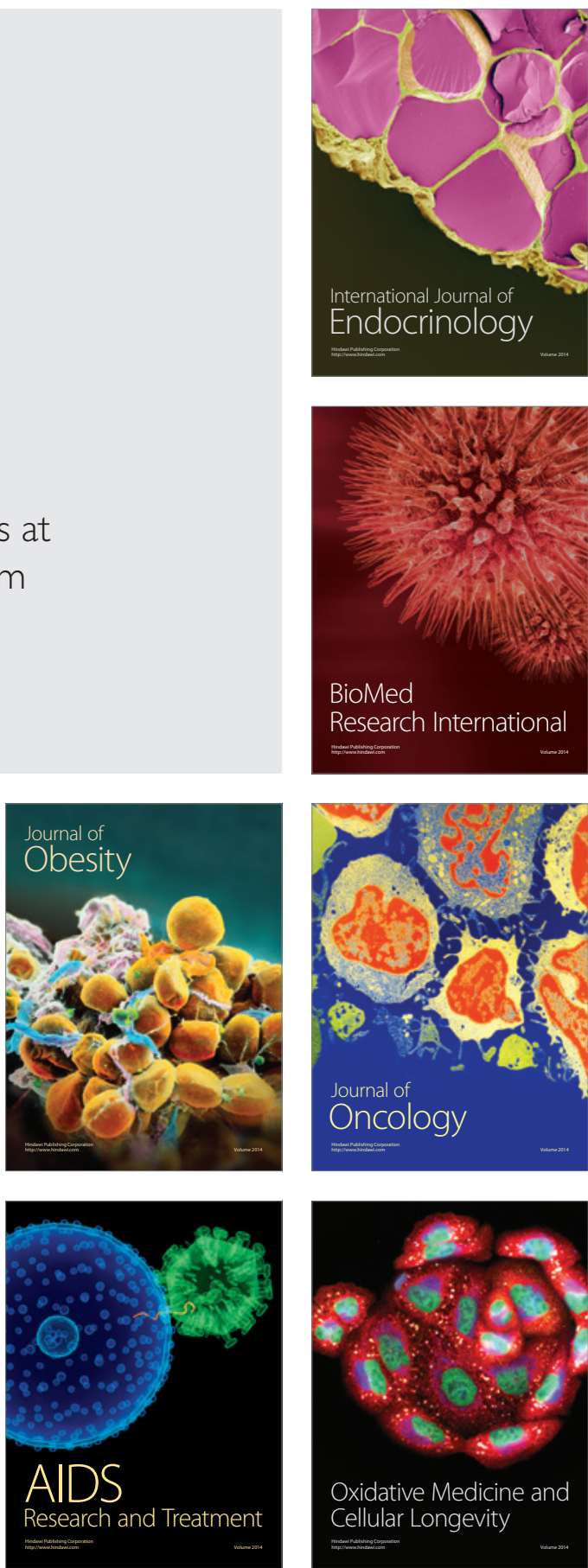